\title{
On the lumped damage modelling of reinforced concrete beams and arches
}

\author{
Thalyson Issac de Jesus Brito, Danilo Menezes Santos, Fabio Augusto Silva Santos, Rafael Nunes \\ da Cunha, David Leonardo Nascimento de Figueiredo Amorim \\ Laboratory of Mathematical Modelling in Civil Engineering, Post-graduation Programme in Civil Engineering, Department of Civil \\ Engineering, Federal University of Sergipe, São Cristóvão, Brazil \\ britothalyson@gmail.com, bttp://orcid.org/0000-0003-0884-2950 \\ dmsantosse@gmail.com, bttp://orcid.org/0000-0002-3165-7553 \\ fabioangustoufs@gmail.com,bttp:/ /orcid.org/0000-0003-0554-2119 \\ fael3005ufs@academico.ufs.br, http://orcid.org/0000-0003-2503-6758 \\ david.amorim@ufs.br,bttp://orcid.org/0000-0002-9233-3114
}

\begin{abstract}
The analysis of reinforced concrete structures can be performed by means of experiments or numerical studies. The first way is usually quite expensive, so the second one sometimes is a good option to understand the physical behaviour of actual structures. Lumped damage mechanics appears as one of the latest nonlinear theories and presents itself as an interesting alternative to analyse the mechanical behaviour of reinforced concrete structures. The lumped damage mechanic applies concepts of the classic fracture and damage mechanics in plastic hinges for nonlinear analysis of reinforced concrete structures. Therefore, this paper deals with a novel physical definition of the correction factor $\gamma$ for cracking evolution that ensures the presented lumped damage model depicts accuracy when it is compared to experimental observations of reinforced concrete beams and arches. Based on such experiments, the numerical analysis showed that $\gamma$ value has upper and lower thresholds, depending on the physical and geometric properties of the reinforced concrete element. Notwithstanding, for $\gamma$ values inside of the proposed interval, there is a best value of $\gamma$.
\end{abstract}

KEYWORDS. Plastic hinges; Lumped damage mechanic; Reinforced concrete; Beams; Arches.

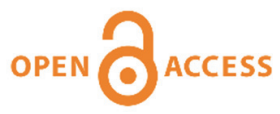

Citation: Brito, T.I.J., Santos, D.M., Santos, F.A.S., Cunha, R.N., Amorim, D.L.N.F., On the lumped damage modelling of reinforced concrete beams and arches, Frattura ed Integrità Strutturale, 54 (2020) 1-20.

Received: 13.04 .2020

Accepted: 29.06 .2020

Published: 01.10 .2020

Copyright: (C) 2020 This is an open access article under the terms of the CC-BY 4.0, which permits unrestricted use, distribution, and reproduction in any medium, provided the original author and source are credited.

\section{INTRODUCTION}

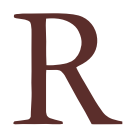
einforced concrete structures are worldwide used. In order to understand the behaviour of reinforced concrete structures due to different loading conditions, several experimental researches were carried out during the last decades. For instance, Vecchio and Emara [1] analysed a reinforced concrete frame with monotonic and cyclic loads. Carpinteti et al. [2] studied the scale effect in concrete specimens under uniaxial compression. Marsavina et al. [3] measured the chloride penetration in concrete structures. Sharifi [4] studied the influence of self-consolidating concrete in 
reinforced concrete beams. Caratelli et al. [5] and Abbas et al. [6] analysed the performance of precast tunnel segments actually built in Italy [5] and Canada [6]. Finally, Ruggiero et al. [7] carried out full scale explosion experiments in reinforced concrete slabs.

Since experimental research is usually quite expensive, numerical studies are often feasible to understand the physical behaviour of actual structures. Among several possibilities, theory of plasticity, fracture and damage mechanics are usually chosen. Theory of plasticity is probably the most known nonlinear principle. In such theory the inelastic effects are quantified by plastic strains e.g. the nonlinear behaviour of the reinforced concrete slabs during the direct contact explosion were modelled by Ruggiero et al. [7] throughout the theory of plasticity coupled with a three-dimensional finite element analysis. Fracture mechanics [8] were developed in order to quantify the propagation of discrete cracks in continuum media. For instance, Shi et al. [9] analysed a plain concrete tunnel lining with tens of thousands of finite elements with a fracture model. Note that the numerical response [9] is quite close to the experimental one [10]. Damage mechanics [11] introduces a variable, called damage, which quantifies the micro-crack density for concrete-like materials or micro-voids for metallic ones. In such theory, these micro-cracks are not small enough to be neglected but not big enough to be considered as discrete cracks. Several damage models were proposed in literature [12-20]. Despite the accuracy of the plastic, damage and fracture models, due to the material complexity of reinforced concrete structures, such models are usually not suitable for practical applications.

Alternatively, lumped damage mechanics (LDM) applies some key concepts of classic fracture and damage mechanics in plastic hinges. LDM was firstly formulated for reinforced concrete structures under seismic loads [21-23]. Afterwards, LDM was rapidly expanded for other reinforced concrete structures [24-32], as well as steel frames [33-36], plain concrete tunnel linings [37] and masonry arches [37-38]. Note that LDM models present objective solutions [39-41].

For reinforced concrete structures the damage variable quantifies the concrete cracking and the plastic rotation variable accounts for the reinforcement yielding. Such damage variable takes values between zero and one. Therefore, the generalised Griffith criterion is used as an energy balance to crack propagation i.e. damage evolution. The plastic rotation evolution is accounted for a kinematic plastic law. Note that the evolution laws for damage and plastic rotation on the referred papers [21-32] and the references therein varies due to the purpose of each study and the applications per se.

Perdomo et al. [23] proposed evolution laws that the model parameters can be easily associated to classic reinforced concrete theory. Despite such model's [23] accuracy for bearing load capacity of reinforced concrete structures, service loads are often not well estimated. As an attempt to present a simple calibration of this model, Alva and El Debs [27] proposed a correction factor that enhances the damage evolution law leading to solutions that are even more accurate. However, Alva and El Debs [27] do not present the physical meaning of such factor, which might be an issue to this model reach practical engineering applications.

In the light of the foregoing, this paper aims to propose a novel understanding of the physical meaning of the correction factor presented by Alva and El Debs [27]. Therefore, such correction factor is widely analysed using some experiments in order to deepen knowledge on the model and facilitate its application in practical engineering problems.

\section{LUMPED DAMAGE MECHANICS}

\section{Statics of circular arch elements}

onsider the structure depicted in Fig. 1a, which is composed by $m$ circular arch elements connected by $n$ nodes. External forces can be applied at each node, as illustrated for node $j\left(P_{u j}, P_{w j}\right.$ and $\left.P_{\theta j}\right)$. Note that the first index of the applied force describes its direction and the second one the node e.g. $P_{w j}$ is the force at the node $j$ parallel to the $Z$ axis. Generically, the applied loads are gathered in the matrix of external forces, given by:

$$
\{\mathbf{P}\}=\left\{\begin{array}{lllllllllllllll}
P_{u 1} & P_{w 1} & P_{\theta 1} & \ldots & P_{u i} & P_{w i} & P_{\theta i} & \ldots & P_{u j} & P_{u j} & P_{\theta j} & \ldots & P_{u n} & P_{w n} & P_{\theta n}
\end{array}\right\}^{T}
$$

where the superscript $T$ means "transpose of".

Consider a circular arch element $b$ between nodes $i$ and $j$, as the one presented in Fig. 1. A circular arch element is defined by its arc angle $\left(\chi_{b}\right)$, a radius $\left(R_{b}\right)$ and an angle between the Z-axis and $z$-axis $\left(\beta_{b}\right)$. Such element presents internal forces with respect to the global XZ system as depicted in Fig. 1b. Then, the matrix of internal forces is given as follows:

$$
\{\mathbf{Q}\}_{b}=\left\{\begin{array}{llllll}
Q_{u i} & Q_{w i} & Q_{\theta i} & Q_{u j} & Q_{w j} & Q_{\theta j}
\end{array}\right\}^{T}
$$


where $Q_{u i}$ is the internal force at the node $i$ in the $X$-axis direction, $Q_{w i}$ is the internal force at the node $i$ in the $Z$-axis direction and so on.

Now, adopting the same notation proposed by Powell [42], another set of static variables is introduced (Fig. 1c) which are called as generalised stresses. Then, the matrix of generalised stresses gathers two bending moments at the edges of the element $\left(M_{i}\right.$ and $\left.M_{j}\right)$ and an axial force at the node $i\left(N_{i}\right)$ i.e.

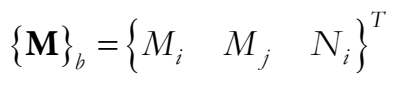

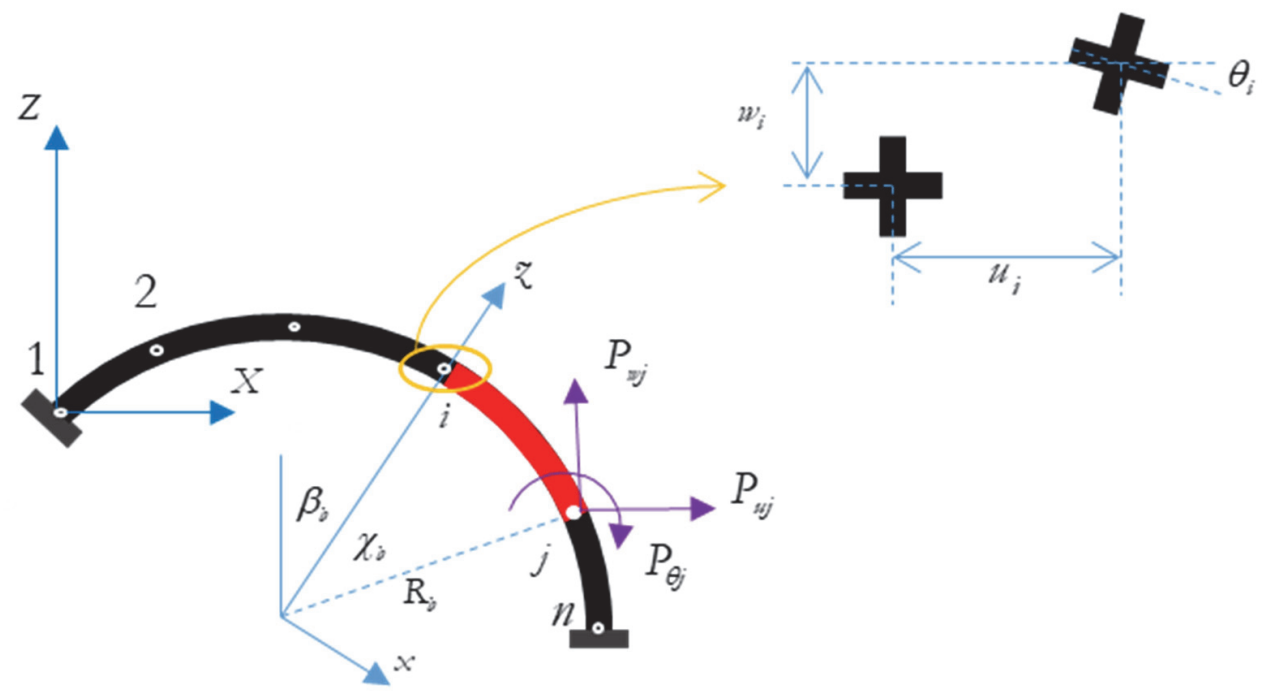

(a)

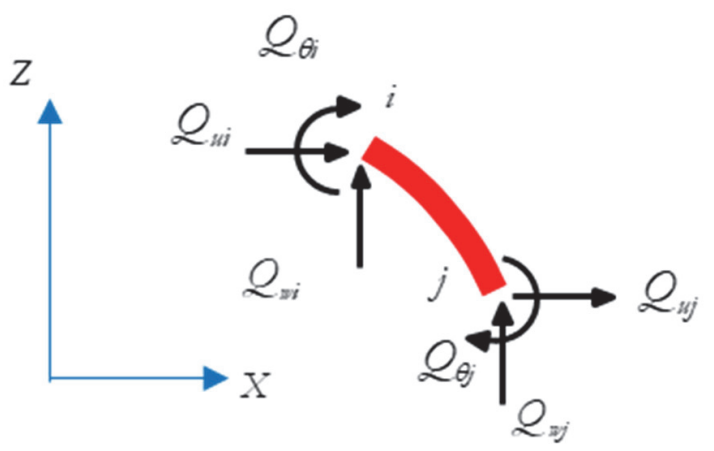

(b)

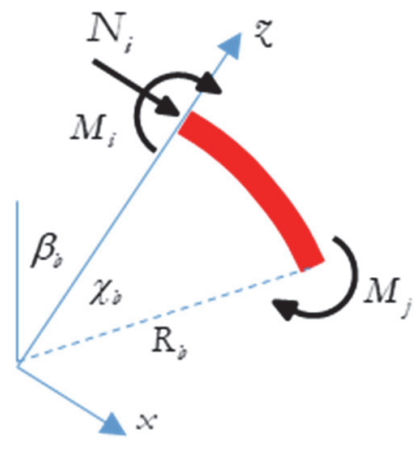

(c)

Figure 1: (a) Structure composed by circular arch finite elements, (b) internal forces and (c) generalised stresses.

Regarding the equilibrium of the element, the internal forces and the generalised stresses can be expressed as [31]:

$$
\{\mathbf{Q}\}_{b}=[\mathbf{B}]_{b}^{T}\{\mathbf{M}\}_{b}
$$

where $[\mathbf{B}]_{b}$ is the transformation matrix, given by: 


$$
\begin{aligned}
& {[\mathbf{B}]_{b}=\left[\begin{array}{ccc}
-\frac{\sin \left(\beta_{b}\right)}{R_{b} \sin \left(\chi_{b}\right)} & -\frac{\cos \left(\beta_{b}\right)}{R_{b} \sin \left(\chi_{b}\right)} & 1 \\
-\frac{\sin \left(\beta_{b}\right)}{R_{b} \sin \left(\chi_{b}\right)} & -\frac{\cos \left(\beta_{b}\right)}{R_{b} \sin \left(\chi_{b}\right)} & 0 \\
\cos \left(\beta_{b}\right)+\frac{\left(\cos \left(\chi_{b}\right)-1\right) \sin \left(\beta_{b}\right)}{\sin \left(\chi_{b}\right)} & -\sin \left(\beta_{b}\right)+\frac{\left(\cos \left(\chi_{b}\right)-1\right) \cos \left(\beta_{b}\right)}{\sin \left(\chi_{b}\right)} & 0
\end{array}\right.} \\
& -\frac{\cos \left(\beta_{b}+\chi_{b}\right)}{R_{b}}+\frac{\cos \left(\chi_{b}\right) \sin \left(\beta_{b}+\chi_{b}\right)}{R_{b} \sin \left(\chi_{b}\right)} \quad \frac{\sin \left(\beta_{b}+\chi_{b}\right)}{R_{b}}+\frac{\cos \left(\chi_{b}\right) \cos \left(\beta_{b}+\chi_{b}\right)}{R_{b} \sin \left(\chi_{b}\right)} \\
& -\frac{\cos \left(\beta_{b}+\chi_{b}\right)}{R_{b}}+\frac{\cos \left(\chi_{b}\right) \sin \left(\beta_{b}+\chi_{b}\right)}{R_{b} \sin \left(\chi_{b}\right)} \quad \frac{\sin \left(\beta_{b}+\chi_{b}\right)}{R_{b}}+\frac{\cos \left(\chi_{b}\right) \cos \left(\beta_{b}+\chi_{b}\right)}{R_{b} \sin \left(\chi_{b}\right)} \quad 1
\end{aligned}
$$

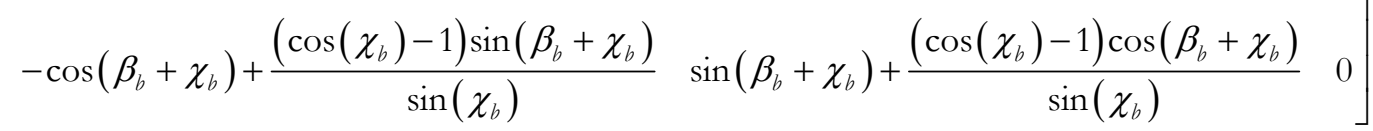

Then, the equilibrium relation of the structure is given by:

$$
\{\mathbf{P}\}=\sum_{b=1}^{m}\left\{\mathbf{Q}_{E}\right\}_{b}
$$

being $\left\{\mathbf{Q}_{E}\right\}_{b}$ the expanded internal forces matrix, given as follows:

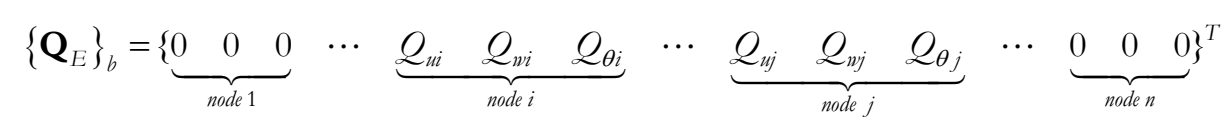

Therefore, the equilibrium relation can be expressed as:

$$
\{\mathbf{P}\}=\sum_{b=1}^{m}\left[\mathbf{B}_{E}\right]_{b}^{T}\{\mathbf{M}\}_{b}
$$

where $\left[\mathbf{B}_{E}\right]_{b}$ is the expanded transformation matrix, given in a similar way of $\left\{\mathbf{Q}_{E}\right\}_{b}$.

\section{Kinematics of circular arch elements}

Consider again the structure depicted in Fig. 1 a, the node $i$ presents two translations parallel to the global $X$ - and $Z$-axes $\left(u_{i}\right.$ and $w_{i}$, respectively) and a rotation in the $X Z$ plane $\left(\theta_{i}\right)$. Such translations and rotation are here called generalised displacements. Then, the generalised displacements of all nodes of the structure are gathered in the generalised displacements matrix, given by:

$$
\{\mathbf{U}\}=\left\{\begin{array}{llllllllllllllll}
u_{1} & w_{1} & \theta_{1} & \ldots & u_{i} & w_{i} & \theta_{i} & \ldots & u_{j} & w_{j} & \theta_{j} & \ldots & u_{n} & w_{n} & \theta_{n}
\end{array}\right\}^{T}
$$

Now, the generalised deformations are defined as conjugate quantities of the generalised stress i.e. $\phi_{i}, \phi_{j}$ and $\delta_{i}$ are conjugated to $M_{i}, M_{j}$ and $N_{i}$, respectively. Such quantities are gathered in the generalised deformations matrix:

$$
\{\boldsymbol{\Phi}\}_{b}=\left\{\varphi_{i} \quad \varphi_{j} \quad \delta_{i}\right\}^{T}
$$

Therefore, the mechanical power of the element is expressed as: 


$$
\{\dot{\boldsymbol{\Phi}}\}_{b}^{T}\{\mathbf{M}\}_{b}=\{\dot{\mathbf{U}}\}^{T}\left\{\mathbf{Q}_{E}\right\}_{b} \quad \forall\{\mathbf{M}\}_{b}
$$

Assuming small displacements and small deformations, the matrix of generalised deformations is given by:

$$
\{\boldsymbol{\Phi}\}_{b}=\left[\mathbf{B}_{E}\right]_{b}\{\mathbf{U}\}
$$

\section{Elasticity of circular arch elements}

Consider an elastic circular arch element with its internal forces at edges in the local coordinate system as the one depicted in Fig. 2a. Thus, the strain energy of the element is expressed by:

$$
U_{b}=\int_{0}^{x_{b}}\left(\frac{M(\psi)^{2}}{2 E I}+\frac{N(\psi)^{2}}{2 A E}\right) \mathrm{R}_{b} d \psi
$$

where $N(\psi)$ and $M(\psi)$ are the normal force and bending moment for a cross section $\psi$, respectively, $A E$ is the axial stiffness and $E I$ is the flexural stiffness of the element.

Note that $N(\psi)$ and $M(\psi)$ can be obtained by equilibrium (Fig. 2b):

$$
\begin{aligned}
& M(\psi)=M_{i}+N_{i} R_{b}(1-\cos \psi)-\sin \psi \frac{\left(M_{i}+M_{j}\right)+n_{i} R_{b}\left(1-\cos \chi_{b}\right)}{\sin \chi_{b}}+N_{i} \cos \psi \\
& R_{b} \sin \chi_{b}
\end{aligned}
$$

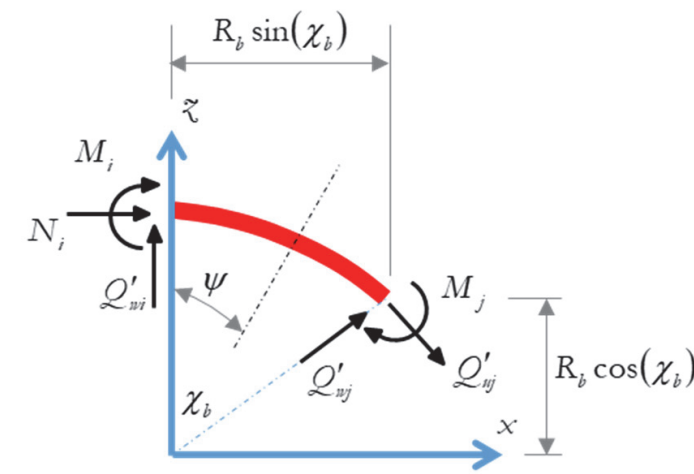

(a)

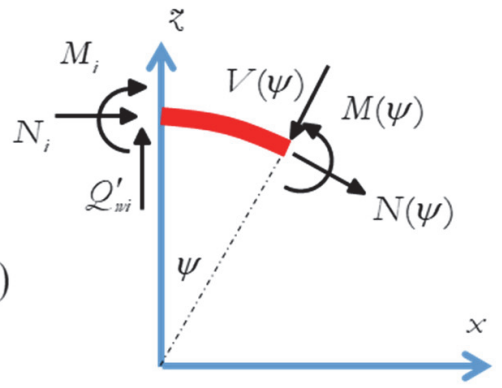

(b)
Figure 2: Elastic circular arch element: (a) internal forces and (b) stresses at any cross section.

where $V(\psi)$ is the shear force for a cross section $\psi$.

By applying Castigliano's Theorem, the elastic generalised deformations are given by:

$$
\left\{\boldsymbol{\Phi}^{e}\right\}_{b}=\left\{\begin{array}{c}
\varphi_{i}^{e} \\
\varphi_{j}^{e} \\
\delta_{i}^{e}
\end{array}\right\}=\left\{\begin{array}{l}
\frac{\partial U_{b}}{\partial M_{i}} \\
\frac{\partial U_{b}}{\partial M_{j}} \\
\frac{\partial U_{b}}{\partial N_{i}}
\end{array}\right\}=\left[\begin{array}{ccc}
\frac{\partial^{2} U_{b}}{\partial M_{i}^{2}} & \frac{\partial^{2} U_{b}}{\partial M_{i} \partial M_{j}} & \frac{\partial^{2} U_{b}}{\partial M_{i} \partial N_{i}} \\
\frac{\partial^{2} U_{b}}{\partial M_{i} \partial M_{j}} & \frac{\partial^{2} U_{b}}{\partial M_{j}^{2}} & \frac{\partial^{2} U_{b}}{\partial M_{j} \partial N_{i}} \\
\frac{\partial^{2} U_{b}}{\partial M_{i} \partial N_{i}} & \frac{\partial^{2} U_{b}}{\partial M_{j} \partial N_{i}} & \frac{\partial^{2} U_{b}}{\partial N_{i}^{2}}
\end{array}\right]\left\{\begin{array}{c}
M_{i} \\
M_{j} \\
N_{i}
\end{array}\right\}_{b}=\left[\mathbf{F}_{0}\right]_{b}\{\mathbf{M}\}_{b}
$$


being $\left[\mathbf{F}_{0}\right]_{b}$ the elastic flexibility matrix, expressed as follows [38]:

$$
\begin{aligned}
& {\left[\mathbf{F}_{0}\right]_{b}=\left[\begin{array}{ccc}
\frac{\partial^{2} U_{b}}{\partial M_{i}^{2}} & \frac{\partial^{2} U_{b}}{\partial M_{i} \partial M_{j}} & \frac{\partial^{2} U_{b}}{\partial M_{i} \partial N_{i}} \\
\frac{\partial^{2} U_{b}}{\partial M_{i} \partial M_{j}} & \frac{\partial^{2} U_{b}}{\partial M_{j}^{2}} & \frac{\partial^{2} U_{b}}{\partial M_{j} \partial N_{i}} \\
\frac{\partial^{2} U_{b}}{\partial M_{i} \partial N_{i}} & \frac{\partial^{2} U_{b}}{\partial M_{j} \partial N_{i}} & \frac{\partial^{2} U_{b}}{\partial N_{i}^{2}}
\end{array}\right]} \\
& \therefore \\
& \frac{\partial^{2} U_{b}}{\partial M_{i}^{2}}=\frac{1}{2} \frac{R_{b}\left(-4 \sin \chi_{b}+3 \chi_{b}-2 \chi_{b} \cos ^{2} \chi_{b}+3 \sin \chi_{b} \cos \chi_{b}\right)}{E I \sin ^{2} \chi_{b}}-\frac{1}{2} \frac{\sin \chi_{b} \cos \chi_{b}-\chi_{b}}{R_{b} A E \sin ^{2} \chi_{b}} \\
& \frac{\partial^{2} U_{b}}{\partial M_{i} \partial M_{j}}=\frac{1}{2} \frac{R_{b}\left(-2 \sin \chi_{b}+\chi_{b}+\sin \chi_{b} \cos \chi_{b}\right)}{E I \sin ^{2} \chi_{b}}-\frac{1}{2} \frac{\sin \chi_{b} \cos \chi_{b}-\chi_{b}}{R_{b} A E \sin ^{2} \chi_{b}} \\
& \frac{\partial^{2} U_{b}}{\partial M_{i} \partial N_{i}}=\frac{1}{2} \frac{R_{b}^{2}\left(-5 \sin \chi_{b}+5 \chi_{b} \cos \chi_{b}-\chi_{b} \cos \chi_{b}-3 \chi_{b}-2 \chi_{b} \cos ^{2} \chi_{b}\right)}{E I \sin ^{2} \chi_{b}} \\
& -\frac{1}{2} \frac{-\chi_{b}-\sin \chi_{b}+\sin \chi_{b} \cos \chi_{b}+\chi_{b} \cos \chi_{b}}{A E \sin ^{2} \chi_{b}} \\
& \frac{\partial^{2} U_{b}}{\partial M_{j}^{2}}=\frac{1}{2} \frac{R_{b}\left(\chi_{b}-\sin \chi_{b} \cos \chi_{b}\right)}{E I \sin ^{2} \chi_{b}}-\frac{1}{2} \frac{\sin \chi_{b} \cos \chi_{b}-\chi_{b}}{R_{b} A E \sin ^{2} \chi_{b}} \\
& \frac{\partial^{2} U_{b}}{\partial M_{j} \partial N_{i}}=\frac{1}{2} \frac{R_{b}^{2}\left(-\sin \chi_{b}-\chi_{b} \cos \chi_{b}+\chi_{b}+\sin \chi_{b} \cos \chi_{b}\right)}{E I \sin ^{2} \chi_{b}} \\
& -\frac{1}{2} \frac{-\chi_{b}-\sin \chi_{b}+\sin \chi_{b} \cos \chi_{b}+\chi_{b} \cos \chi_{b}}{A E \sin ^{2} \chi_{b}} \\
& \frac{\partial^{2} U_{b}}{\partial N_{i}^{2}}=\frac{R_{b}^{3}\left(-3 \sin \chi_{b}-\chi_{b} \cos ^{2} \chi_{b}-\chi_{b} \cos \chi_{b}+2 \chi_{b}+3 \sin \chi_{b} \cos \chi_{b}\right)}{E I \sin ^{2} \chi_{b}} \\
& -\frac{R_{b}\left(-\chi_{b}-\sin \chi_{b}+\sin \chi_{b} \cos \chi_{b}+\chi_{b} \cos \chi_{b}\right)}{A E \sin ^{2} \chi_{b}}
\end{aligned}
$$

\section{Deformation equivalence bypothesis}

For the sake of simplicity, consider initially a uniaxial problem where a damaged straight bar is axially loaded. By definition, the damage variable $\omega$ represents the micro-cracks density [11]. Then, such bar resists to the axial force by means of the effective stress i.e. the Cauchy stress $\sigma$ divided by $(1-\omega)$. The following expression, named strain equivalence hypothesis [11], is given by substituting the effective stress in the Hooke's law:

$$
\tilde{\sigma}=\frac{\sigma}{1-\omega}=E\left(\varepsilon-\varepsilon^{p}\right)
$$

where $E$ is the Young's modulus, $\varepsilon$ is the total strain and $\varepsilon^{p}$ is the plastic strain. The previous relation can be rewritten as follows:

$$
\varepsilon=\frac{\sigma}{(1-\omega) E}+\varepsilon^{p}=\frac{\sigma}{E}+\frac{\omega \sigma}{(1-\omega) E}+\varepsilon^{p}=\varepsilon^{e}+\varepsilon^{d}+\varepsilon^{p}
$$


Therefore, by assuming the strain equivalence hypothesis the total strain can be expressed by a sum of three parts: elastic, damaged and plastic ones. Note that if $\omega=0$ then $\varepsilon^{d}=0$; on the other hand, if $\omega$ tends to one, $\varepsilon^{d}$ tends to infinity, which represents that the straight bar is now broken into two parts.

Analogously, for a circular arch element the deformation equivalence hypothesis can be defined as:

$$
\{\boldsymbol{\Phi}\}_{b}=\left\{\boldsymbol{\Phi}^{e}\right\}_{b}+\left\{\boldsymbol{\Phi}^{d}\right\}_{b}+\left\{\boldsymbol{\Phi}^{p}\right\}_{b}
$$

being $\left\{\boldsymbol{\Phi}^{e}\right\}_{b},\left\{\boldsymbol{\Phi}^{d}\right\}_{b}$ and $\{\boldsymbol{\Phi}\}_{b}$ the elastic, damaged and plastic generalised deformations matrices, respectively.

For the lumped damage framework, $\{\boldsymbol{\Phi} /\}_{b}$ and $\{\boldsymbol{\Phi}\}_{b}$ describe the inelastic effects that are concentrated at two hinges at the edges of the element (Fig. 3). In this paper it is assumed that the plastic deformations account for the reinforcement yielding and the lumped damage variables represent the concrete cracking.

Assuming that the plastic elongations at both hinges can be neglected [38], the plastic generalised deformation matrix is given by:

$$
\left\{\boldsymbol{\Phi}^{p}\right\}_{b}=\left\{\begin{array}{lll}
\varphi_{i}^{p} & \varphi_{j}^{p} & 0
\end{array}\right\}^{T}
$$

where $\phi^{p}$ and $\phi^{p}$ are the plastic relative rotations at the edges $i$ and $j$ of the element, respectively.

The damaged generalised deformation matrix is expressed as:

$$
\left\{\boldsymbol{\Phi}^{d}\right\}_{b}=\left[\begin{array}{ccc}
\frac{d_{i}}{1-d_{i}} \frac{\partial^{2} U_{b}}{\partial M_{i}^{2}} & 0 & 0 \\
0 & \frac{d_{j}}{1-d_{j}} \frac{\partial^{2} U_{b}}{\partial M_{j}^{2}} & 0 \\
0 & 0 & 0
\end{array}\right]\left\{\begin{array}{c}
M_{i} \\
M_{j} \\
N_{i}
\end{array}\right\}_{b}=\left[\mathbf{C}\left(d_{i}, d_{j}\right)\right]_{b}\{\mathbf{M}\}_{b}
$$

being $\left[\mathbf{C}\left(d_{i}, d_{j}\right)\right]_{b}$ the compliance matrix and $d_{i}$ and $d_{j}$ the lumped damage variables at the hinges $i$ and $j$, respectively. Note that if there is no damage at the element then $\left[\mathbf{C}\left(d_{i}, d_{j}\right)\right]_{b}$ is null; on the other hand, if the damage variables tend to one then the non-zero terms of $\left[\mathbf{C}\left(d_{i}, d_{j}\right)\right]_{b}$ tend to infinity, which represents that the inelastic hinges are close to perfectly hinges. Then, by substituting (15), (20) and (21) in (19), the constitutive relation is given by:

$$
\left\{\boldsymbol{\Phi}-\boldsymbol{\Phi}^{p}\right\}_{b}=\left[\mathbf{F}_{0}\right]_{b}\{\mathbf{M}\}_{b}+\left[\mathbf{C}\left(d_{i}, d_{j}\right)\right]_{b}\{\mathbf{M}\}_{b}=\left[\mathbf{F}\left(d_{i}, d_{j}\right)\right]_{b}\{\mathbf{M}\}_{b}
$$

where $\left[\mathbf{F}\left(d_{i}, d_{j}\right)\right]_{b}$ is the flexibility matrix with damage, written as:

$$
\left[\mathbf{F}\left(d_{i}, d_{j}\right)\right]_{b}=\left[\begin{array}{ccc}
\frac{1}{1-d_{i}} \frac{\partial^{2} U_{b}}{\partial M_{i}^{2}} & \frac{\partial^{2} U_{b}}{\partial M_{i} \partial M_{j}} & \frac{\partial^{2} U_{b}}{\partial M_{i} \partial N_{i}} \\
\frac{\partial^{2} U_{b}}{\partial M_{i} \partial M_{j}} & \frac{1}{1-d_{j}} \frac{\partial^{2} U_{b}}{\partial M_{j}^{2}} & \frac{\partial^{2} U_{b}}{\partial M_{j} \partial N_{i}} \\
\frac{\partial^{2} U_{b}}{\partial M_{i} \partial N_{i}} & \frac{\partial^{2} U_{b}}{\partial M_{j} \partial N_{i}} & \frac{\partial^{2} U_{b}}{\partial N_{i}^{2}}
\end{array}\right]
$$




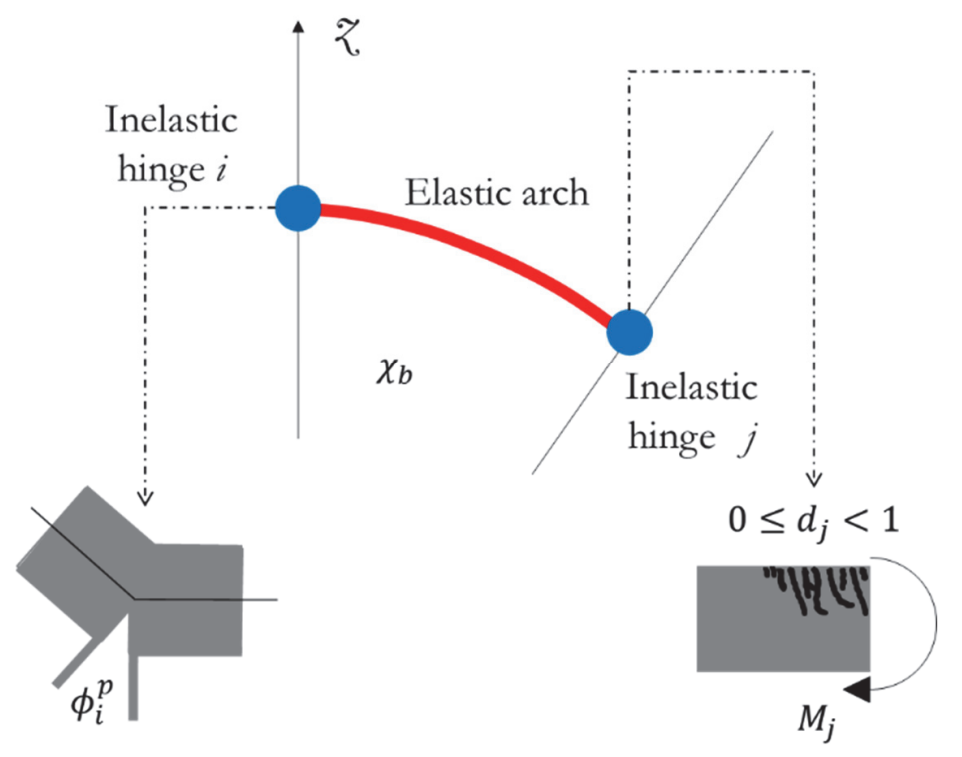

Figure 3: Elastic circular arch element with two inelastic hinges.

\section{Model reduction to straight elements}

A particular characteristic of the presented lumped damage model is that the circular arch element can degenerate to a straight element [37]. Therewith, if $\mathrm{R}_{b}$ tends to infinity then $\chi_{b}$ tends to zero, $R_{b} \sin \chi_{b}$ tends to the length of the element $L_{b}$ and $\beta_{b}$ becomes its orientation. Then, the transformation and flexibility matrices are given as follows:

$$
\begin{gathered}
\lim _{R_{b} \rightarrow \infty}[\mathbf{B}]_{b}=\left[\begin{array}{cccccc}
-\frac{\sin \beta_{b}}{L_{b}} & -\frac{\cos \beta_{b}}{L_{b}} & 1 & \frac{\sin \beta_{b}}{L_{b}} & \frac{\cos \beta_{b}}{L_{b}} & 0 \\
-\frac{\sin \beta_{b}}{L_{b}} & -\frac{\cos \beta_{b}}{L_{b}} & 0 & \frac{\sin \beta_{b}}{L_{b}} & \frac{\cos \beta_{b}}{L_{b}} & 1 \\
\cos \beta_{b} & -\sin \beta_{b} & 0 & -\cos \beta_{b} & \sin \beta_{b} & 0
\end{array}\right] \\
\lim _{\mathrm{R}_{b} \rightarrow \infty}\left[\mathbf{F}\left(d_{i}, d_{j}\right)\right]_{b}=\left[\begin{array}{cccc}
\frac{1}{1-d_{i} \frac{L_{b}}{3 E I}} & -\frac{L_{b}}{6 E I} & 0 \\
-\frac{L_{b}}{6 E I} & \frac{1}{1-d_{j}} \frac{L_{b}}{3 E I} & 0 \\
0 & 0 & \frac{L_{b}}{A E}
\end{array}\right]
\end{gathered}
$$

Damage evolution law

The complementary energy of the element is given by:

$$
W=\frac{1}{2}\{\mathbf{M}\}_{b}^{T}\left\{\boldsymbol{\Phi}-\boldsymbol{\Phi}^{p}\right\}_{b}=\frac{1}{2}\{\mathbf{M}\}_{b}^{T}\left[\mathbf{F}\left(d_{i}, d_{j}\right)\right]_{b}\{\mathbf{M}\}_{b}
$$

Since the lumped damage variable accounts for the concrete cracking, its evolution law is given by the generalised Griffith criterion for each hinge i.e. 


$$
\begin{aligned}
& \left\{\begin{array}{l}
\Delta d_{i}>0 \quad \Rightarrow \quad G_{i}=Y\left(d_{i}\right) \\
G_{i}<Y\left(d_{i}\right) \quad \Rightarrow \quad \Delta d_{i}=0
\end{array} \quad \therefore G_{i}=\frac{\partial W}{\partial d_{i}}=\frac{M_{i}^{2}}{2\left(1-d_{i}\right)^{2}} \frac{\partial^{2} U_{b}}{\partial M_{i}^{2}}\right. \\
& \left\{\begin{array}{l}
\Delta d_{j}>0 \quad \Rightarrow G_{j}=Y\left(d_{j}\right) \\
G_{j}<Y\left(d_{j}\right) \Rightarrow \Delta d_{j}=0
\end{array} \quad \therefore G_{j}=\frac{\partial W}{\partial d_{j}}=\frac{M_{j}^{2}}{2\left(1-d_{j}\right)^{2}} \frac{\partial^{2} U_{b}}{\partial M_{j}^{2}}\right.
\end{aligned}
$$

where $G_{i}$ and $G_{j}$ are the damage driving moments for the hinges $i$ and $j$, respectively, and $Y\left(d_{i}\right)$ and $Y\left(d_{j}\right)$ are the cracking resistance functions.

The cracking resistance function for a hinge $i$ was obtained by means of experiments on reinforced concrete beams [23]:

$$
Y\left(d_{i}\right)=Y_{0}+q \frac{\ln \left(1-d_{i}\right)}{1-d_{i}}
$$

being $Y_{0}$ and $q$ model parameters.

In order to generalise the previous equation, Alva and El Debs [27] proposed the following relation:

$$
Y\left(d_{i}\right)=Y_{0}+q \exp \left[-\gamma\left(1-d_{i}\right)\right] \frac{\ln \left(1-d_{i}\right)}{1-d_{i}}
$$

where $\gamma$ is an empiric parameter introduced as an attempt to ensure a better fitting between numerical and experimental responses for service loads.

\section{Plastic evolution law}

The plastic evolution laws for each hinge of the element are given by:

$$
\begin{aligned}
& \left\{\begin{array}{lll}
\Delta \varphi_{i}^{p}>0 & \Rightarrow f_{i}=0 & \therefore f_{i}=\left|\frac{M_{i}}{1-d_{i}}-C \varphi_{i}^{p}\right|-k_{0} \leq 0 \\
f_{i}<0 & \Rightarrow \Delta \varphi_{i}^{p}=0 &
\end{array}\right. \\
& \left\{\begin{array}{lll}
\Delta \varphi_{j}^{p}>0 & \Rightarrow f_{j}=0 & \therefore f_{j}=\left|\frac{M_{j}}{1-d_{j}}-C \varphi_{j}^{p}\right|-k_{0} \leq 0 \\
f_{j}<0 & \Rightarrow \Delta \varphi_{j}^{p}=0 &
\end{array}\right.
\end{aligned}
$$

being $f_{i}$ and $f_{j}$ the yield functions for the hinges $i$ and $j$, respectively, and $C$ and $k_{0}$ model parameters.

\section{MODEL ASSOCIATION WITH REINFORCED CONCRETE THEORY}

A $\mathrm{n}$ evident advantage of the lumped damage models for reinforced concrete structures is that the model parameters can be easily associated to the classic reinforced concrete theory. An engineer in practice knows how to calculate four key quantities for any reinforced concrete element: first cracking moment $\left(M_{r}\right)$, ultimate moment $\left(M_{u}\right)$, plastic moment $\left(M_{p}\right)$ and ultimate plastic rotation $\left(\phi_{t} p\right)$ [43].

Considering an inelastic hinge $i$, cracks start to nucleate when the first cracking moment is reached i.e.

$$
M_{i}=M_{r} \Rightarrow d_{i}=0 \Rightarrow \frac{M_{r}^{2}}{2} \frac{\partial^{2} U_{b}}{\partial M_{i}^{2}}=Y_{0}
$$

Then, the parameter $Y_{0}$ is defined as the first cracking resistance. 
Note that the analysed cross section (hinge $\imath$ ) has a load bearing capacity, therefore the ultimate moment $\left(M_{u}\right)$ is associated to a certain cracking level, which is quantified by the ultimate damage $\left(d_{u}\right)$. Therewith, the generalised Griffith criterion is expressed as:

$$
M_{i}=M_{u} \Rightarrow d_{i}=d_{u} \Rightarrow \frac{M_{u}^{2}}{2\left(1-d_{u}\right)^{2}} \frac{\partial^{2} U_{b}}{\partial M_{i}^{2}}=Y_{0}+q \exp \left[-\gamma\left(1-d_{u}\right)\right] \frac{\ln \left(1-d_{u}\right)}{1-d_{u}}
$$

where $q$ and $d_{u}$ are the unknown variables.

Since the load bearing point $\left(d_{u}, M_{u}\right)$ is the local maximum point of the moment-damage curve, another equation may be defined as:

$$
\left.\frac{\partial M_{i}}{\partial d_{i}}\right|_{\substack{M_{i}=M_{u} \\ d_{i}=d_{u}}}=0 \Rightarrow 2 Y_{0}\left(1-d_{u}\right)+q\left[1+\ln \left(1-d_{u}\right)-\gamma\left(1-d_{u}\right) \ln \left(1-d_{u}\right)\right] \exp \left[-\gamma\left(1-d_{u}\right)\right]=0
$$

Then, with Eqns. (31) and (32) the variables $q$ and $d_{u}$ can be calculated. Note that the parameter $q$ is related to an additional cracking resistance due to the reinforcement.

Analogously to the load bearing point, the plastic moment $\left(M_{p}\right)$ is associated to the plastic damage $\left(d_{p}\right)$. Thus, $d_{p}$ is calculated by the generalised Griffith criterion i.e.

$$
M_{i}=M_{p} \Rightarrow d_{i}=d_{p} \Rightarrow \frac{M_{p}^{2}}{2\left(1-d_{p}\right)^{2}} \frac{\partial^{2} U_{b}}{\partial M_{i}^{2}}=Y_{0}+q \exp \left[-\gamma\left(1-d_{p}\right)\right] \frac{\ln \left(1-d_{p}\right)}{1-d_{p}}
$$

At this stage, the reinforcement starts yielding, therefore:

$$
M_{i}=M_{p} \Rightarrow \varphi_{i}^{p}=0 \Rightarrow f_{i}=0 \Rightarrow k_{0}=\frac{M_{p}}{1-d_{p}}
$$

where $k_{0}$ is defined as the effective plastic moment.

Finally, for the load bearing capacity the plastic evolution law is expressed by:

$$
M_{i}=M_{p} \Rightarrow \varphi_{i}^{p}=\varphi_{u}^{p} \Rightarrow f_{i}=0 \Rightarrow C=\frac{1}{\varphi_{u}^{p}}\left(\frac{M_{u}}{1-d_{u}}-k_{0}\right)
$$

being $C$ then defined.

\section{EXAMPLES}

\section{Cantilever beam [43]}

7 lórez-López et al. [43] presents the test of a cantilever reinforced concrete beam subject to a lateral concentrated load as illustrated in Fig. 4. The beam properties are shown in Tab. 1 and the yield and rupture tensions of the steel bars are $412 \mathrm{MPa}$ and $520 \mathrm{MPa}$, respectively. The numerical analyses carried out in this example vary the value of $\gamma$. The comparison among experimental and numerical responses is shown in Fig. 5.

\begin{tabular}{cccccc}
\hline Beam & $\mathrm{f}_{\mathrm{c}}^{\prime}(\mathrm{MPa})$ & $\mathrm{A}_{\mathrm{s}}$ & $\mathrm{A}_{\mathrm{s}}^{\prime}$ & $\mathrm{h}(\mathrm{cm})$ & $\mathrm{b}(\mathrm{cm})$ \\
1 & 26.0 & $3 \varnothing 12.5 \mathrm{~mm}$ & $3 \varnothing 12.5 \mathrm{~mm}$ & 20 & 20 \\
\hline
\end{tabular}

Table 1: Geometric and material proprieties of the beam [43] 


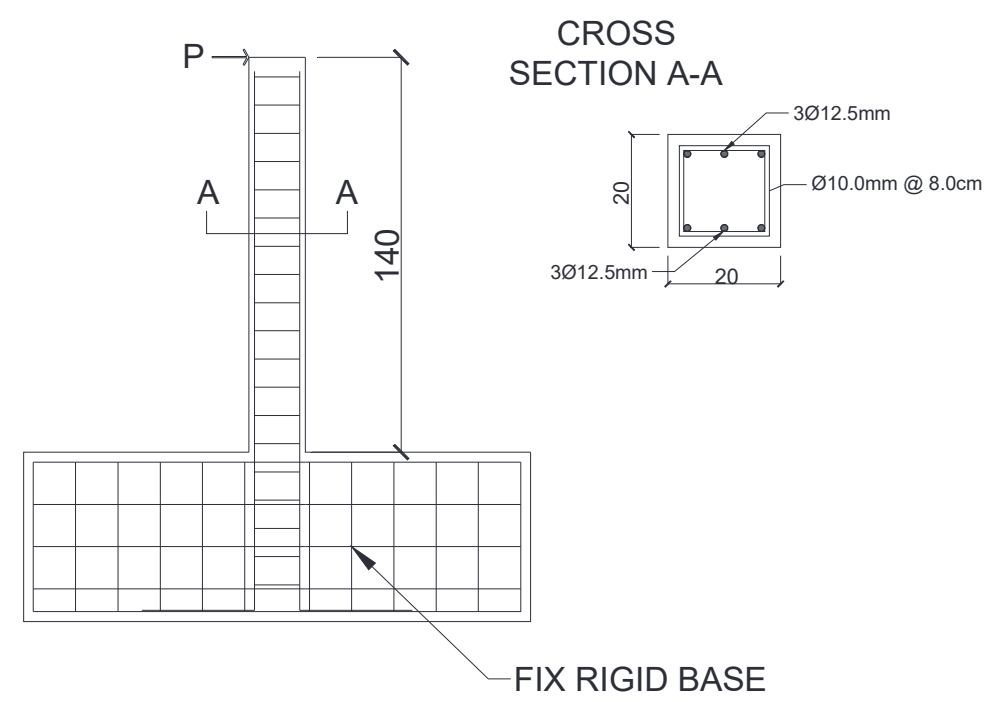

DIMENSIONS IN CENTIMETERS

Figure 4: Test set-up [43]
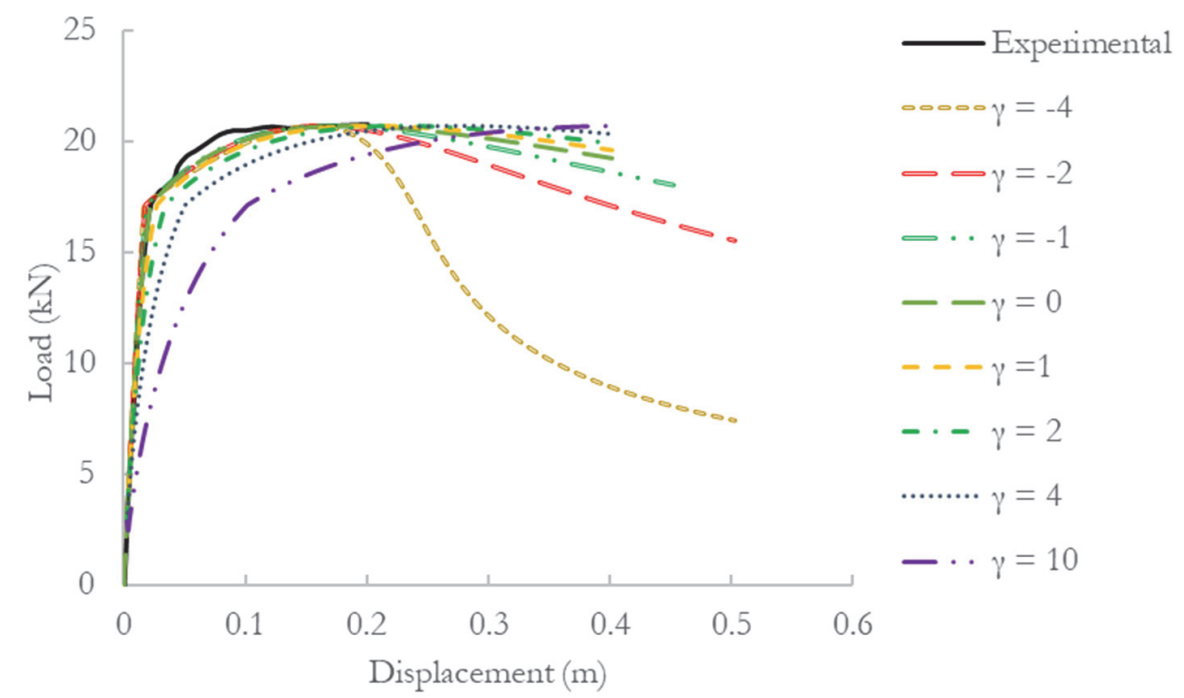

Figure 5: Convergence of results to the experimental for the cantilever beam [43]

For $\gamma=0$, it may be noted that the results are very close to the experimental data, presenting good fitting for the three stages, reaching the rupture load. For $\gamma \neq 0$, it can be observed that all analysis reached the rupture load acquired from experimental data. In cases where the range for $\gamma$ values are lower than zero, the curves present a high stiffness at cracking concrete stage, not fitting well to the experimental result. On the other hand, for the range where $\gamma$ values are higher than zero, there is a decrease in the stiffness response for elastic and cracking stages, but in tertiary stage the similarity with the experimental results is recovered. Furthermore, the Bending Moment vs Damage results are presented in Fig. 6.

As shown in Fig. 6, the ultimate damage $\left(d_{i}\right)$ for $\gamma=0$ is near to 0.6. In comparison, for different $\gamma$ values, it is noted that the damage variable is directly proportional to the coefficient $\gamma$.

In the same way, seen in Fig. 6 when attributed $\gamma$ equal to 10, leads to a physical divergence where it occurs damage growth in parallel bending moment decreases. This fact leads the conclusion that $\gamma$ has a maximum limit. For this, it is necessary to obtain the moment equation that is done by equalling the damage driving moment $(G)$ to cracking resistance function $(Y)$. Then, the upper-limit for $\gamma$ is given by the following criterion: 


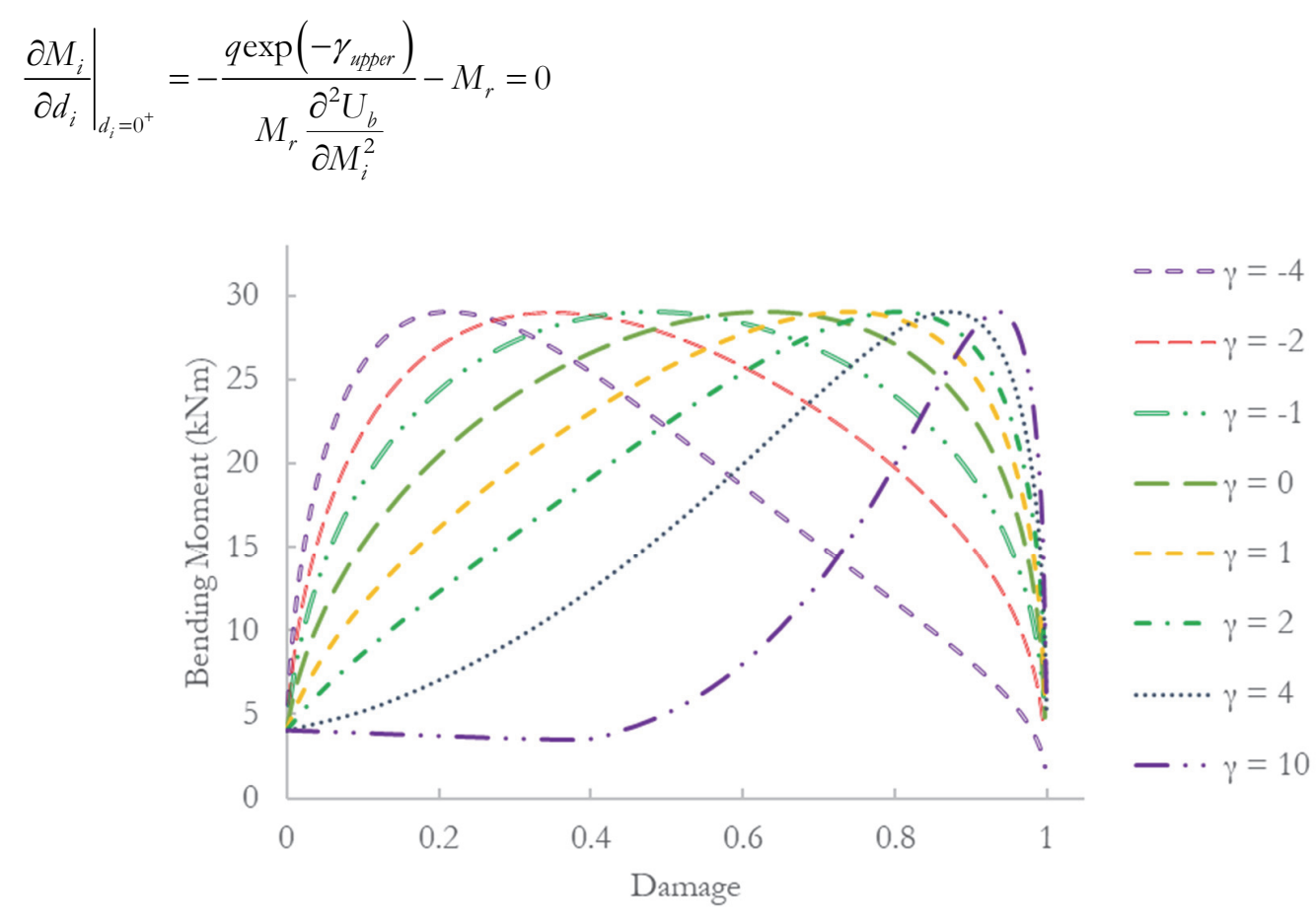

Figure 6: Bending Moment vs. Damage response

The following equation shows the result obtained:

$$
\gamma_{\text {upper }}=-\ln \left(-\frac{M_{r}^{2}}{q} \frac{\partial^{2} U_{b}}{\partial M_{i}^{2}}\right)
$$

The lower-limit for $\gamma$ is obtained by the following criterion:

$$
\left.\frac{\partial d_{i}}{\partial M_{i}}\right|_{d_{i}=0^{+}}=0 \Rightarrow-\frac{M_{r} \frac{\partial^{2} U_{b}}{\partial M_{i}^{2}}}{\frac{1}{\exp \left(\gamma_{\text {lower }}\right)}\left[2 Y_{0} \exp \left(\gamma_{\text {lower }}\right)+q\right]}=0
$$

which leads to:

$$
\gamma_{\text {lower }}=-\infty
$$

Despite $\gamma_{\text {lower, }}$, when $\gamma$ values are negative occurs numerical instabilities in the analysis process, leading to values of ultimate damage and plastic damage tending to zero. Therefore, from now on, only positive values for $\gamma$ are adopted in this paper.

\section{Meneghetti [44]}

A simply supported experimental beam under a four point bending test was carried out by Meneghetti et al. [44], which has as cross section dimensions $15 \mathrm{~cm} \times 30 \mathrm{~cm}$, total length $300 \mathrm{~cm}$ and distance between supports $285 \mathrm{~cm}$. For the design due to bending were defined two longitudinal lower bars with $12.5 \mathrm{~mm}$ diameter, $317 \mathrm{~cm}$ total length and $10 \mathrm{~cm}$ anchorage at each edge; two longitudinal upper bars with $6.3 \mathrm{~mm}$ diameter, $297 \mathrm{~cm}$ total length. For the design due to shearing were calculated 42 stirrups with $6.3 \mathrm{~mm}$ diameter, $7 \mathrm{~cm}$ spacing, $90 \mathrm{~cm}$ total length and $6 \mathrm{~cm}$ anchorage at each tip and the covering adopted was $15 \mathrm{~mm}$ (see Fig. 7). Results of strength limits, $6.3 \mathrm{~mm}$ steel bars acquired the followed magnitude tensions, $508 \mathrm{MPa}$ and $713 \mathrm{MPa}$, yield and rupture, respectively. $12.5 \mathrm{~mm}$ bars acquired yield tension value $578 \mathrm{MPa}$ and 
$806 \mathrm{MPa}$ in rupture. The concrete used achieved average values of $41.4 \mathrm{MPa}$ in the experiments of compressive strength and $37.6 \mathrm{GPa}$ as elasticity modulus. The beam was loaded at its first and second third of its length between supports.
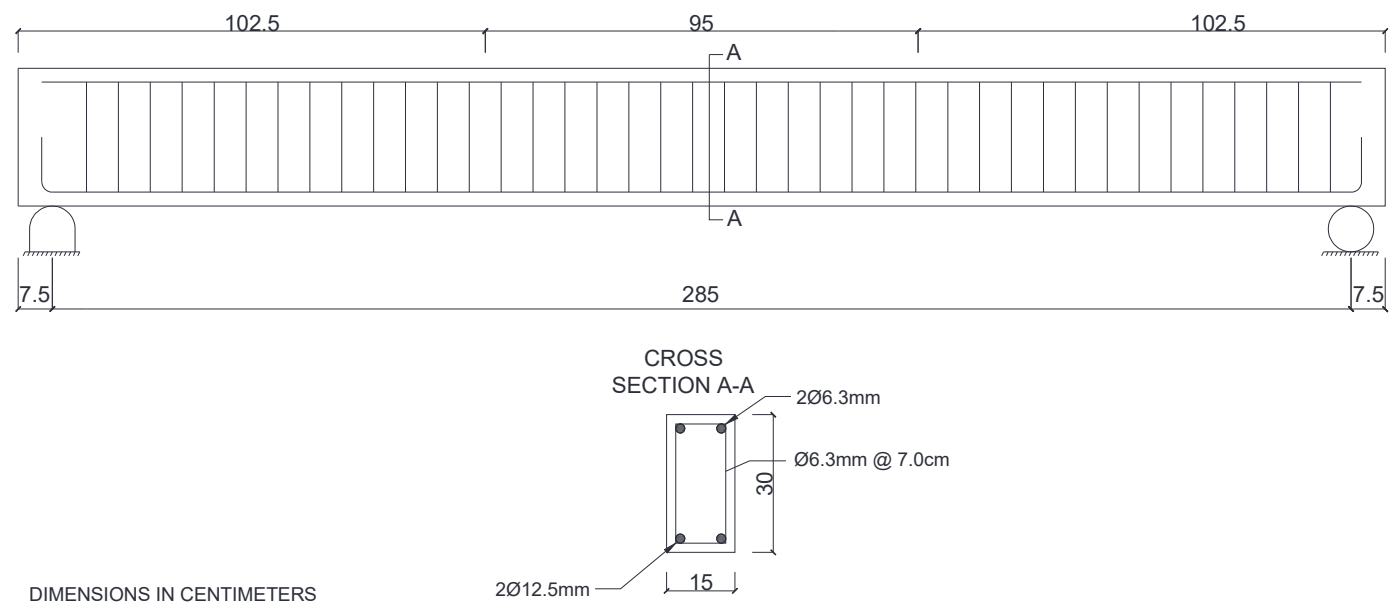

Figure 7: Geometry and typical reinforcement arrangement [44]

Fig. 8 shows a sequence of curves with increasing coefficient $\gamma$ in comparison to the experimental curve. As the coefficient increases it is noticed the numerical model convergence to the experimental loading-displacement curve in this example. Alva [45] suggests that each structure analysed has its optimum coefficient $\left(\gamma_{\mathrm{opt}}\right)$, which might be acquired through repeatedly iterations in a programming routine. The choice of $\gamma$ parameter aim the best numerical fitting to the experimental response. The comparison between the force-displacement curve of the theoretical model and the experimental curve indicates that the lumped damage model is able to approximately reproduce the nonlinear behaviour of the structure, both in the cantilever beam (previous example) and in the current one, which deals with a four-point bending test. It is important to emphasise that all parameters from the numerical model were calculated based on average values of strength and deformability for the structural materials, since the objective was a comparison with experimental results.

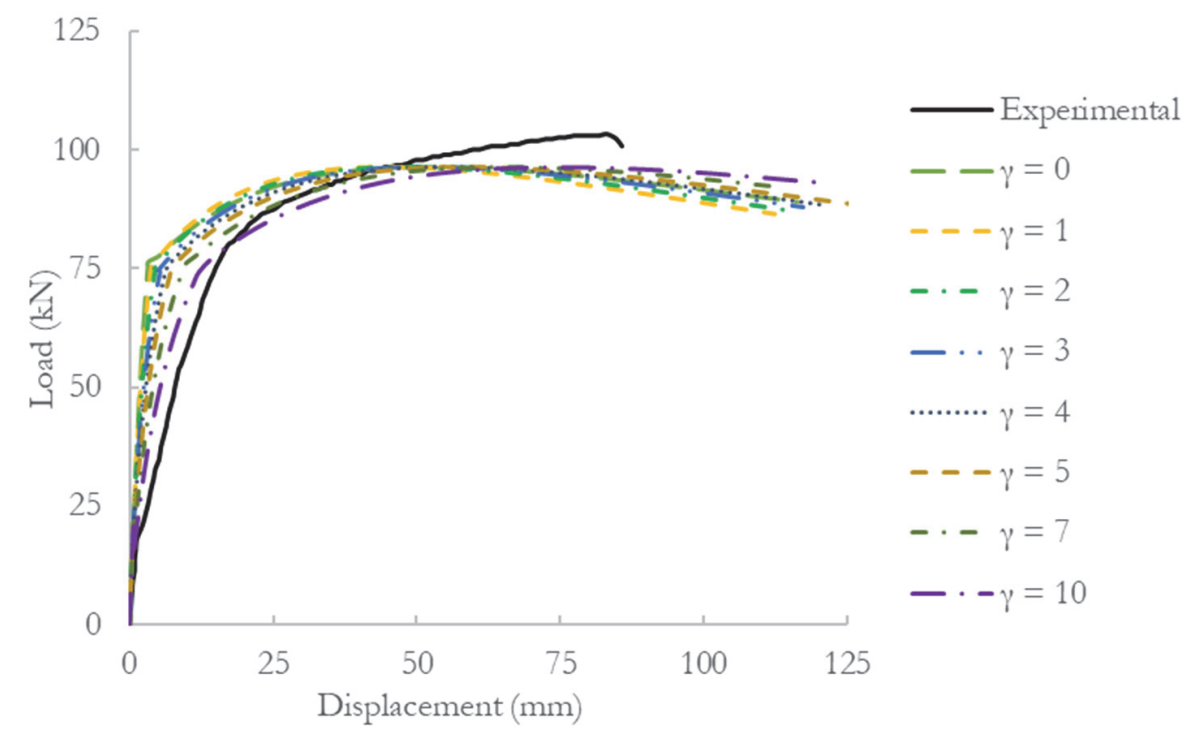

Figure 8: Convergence of results to the experimental beam [44]

\section{Yasser Sharifi Beams [4]}

Sharifi [4] studied the influence of self-consolidating concrete in reinforced concrete beams. For this, a series of experiments in beams, with different reinforcement ratios, were executed, tested under four points bending test. The typical geometry of the beams and its typical arrangement of reinforcement are shown in Fig. 9. The properties of the beams analysed are presented in Tab. 2 and the average yield strength of the longitudinal reinforcement was approximately $400 \mathrm{MPa}$. 


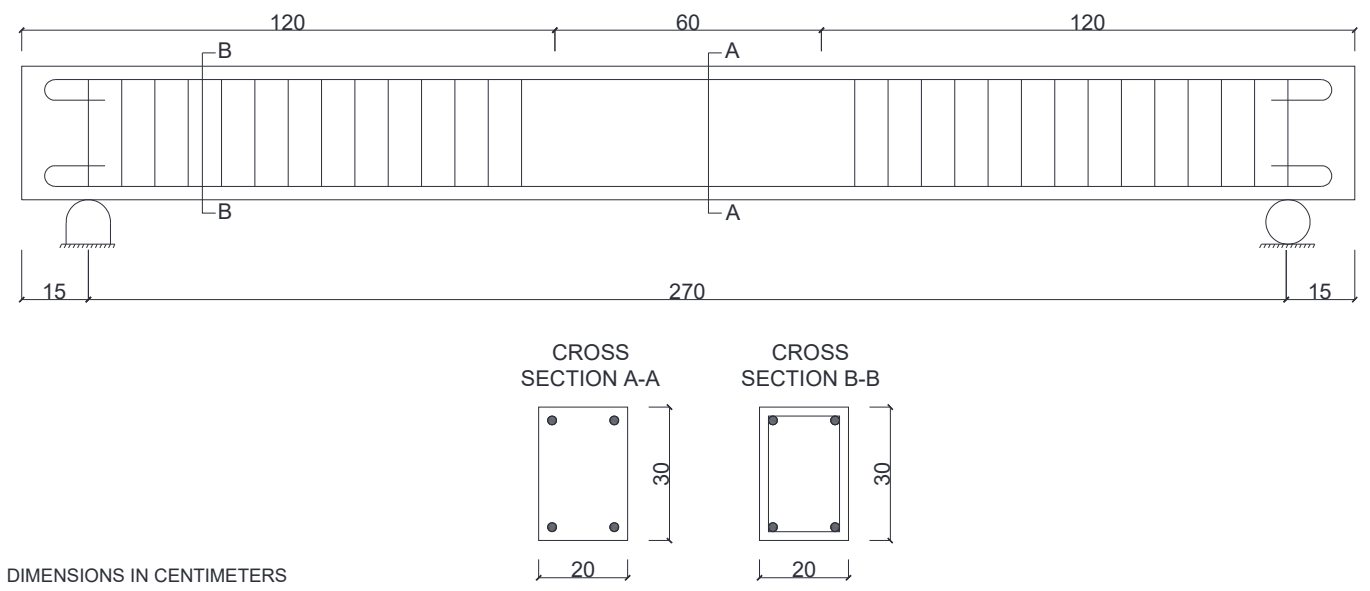

Figure 9: Geometry and typical reinforcement arrangement of the beams [4].

\begin{tabular}{cccccc}
\hline Beam & $\mathrm{f}_{\mathrm{c}}^{\prime}(\mathrm{MPa})$ & $\mathrm{A}_{\mathrm{s}}$ & $\mathrm{A}_{\mathrm{s}}^{\prime}$ & $\mathrm{d}(\mathrm{mm})$ & $\mathrm{d}^{\prime}(\mathrm{mm})$ \\
$\mathrm{B} 1$ & 31.6 & $2 \varnothing 14$ & $2 \varnothing 14$ & 258 & 42 \\
B2 & 28.84 & $2 \varnothing 18+2 \varnothing 16+2 \varnothing 14$ & $2 \varnothing 14+2 \varnothing 18$ & 256 & 43 \\
B3 & 29.53 & $2 \varnothing 22$ & $2 \varnothing 14+2 \varnothing 25$ & 254 & 45 \\
\hline
\end{tabular}

Table 2: Geometric and material proprieties of the Sharifi's beams [4].

For the specimen B1 it was observed that all analyses had good approximation with the experimental results for the three stages and reached the collapse load. The obtained results are shown in Fig. 10.

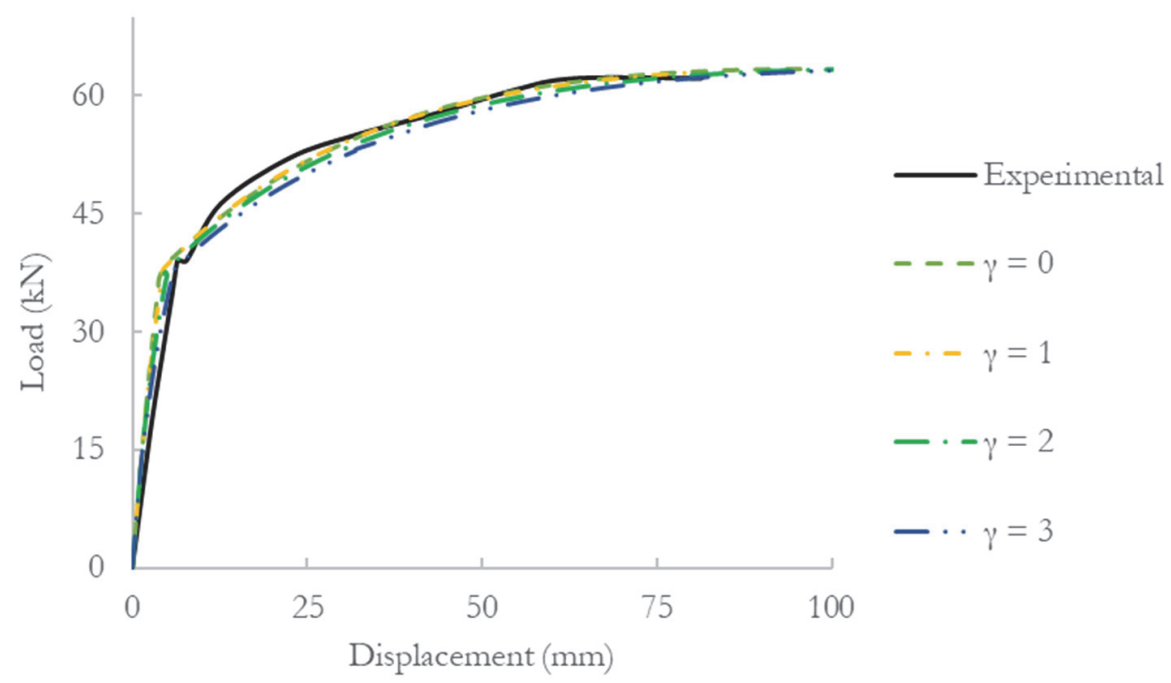

Figure 10: Convergence of results to the experimental beam B1 [4]

Furthermore, all curves present closer results to the experimental curve at primary stage, but for higher values of $\gamma$, the stiffness is closest than the others. For B2, the results of load-displacement are shown in Fig. 11. 


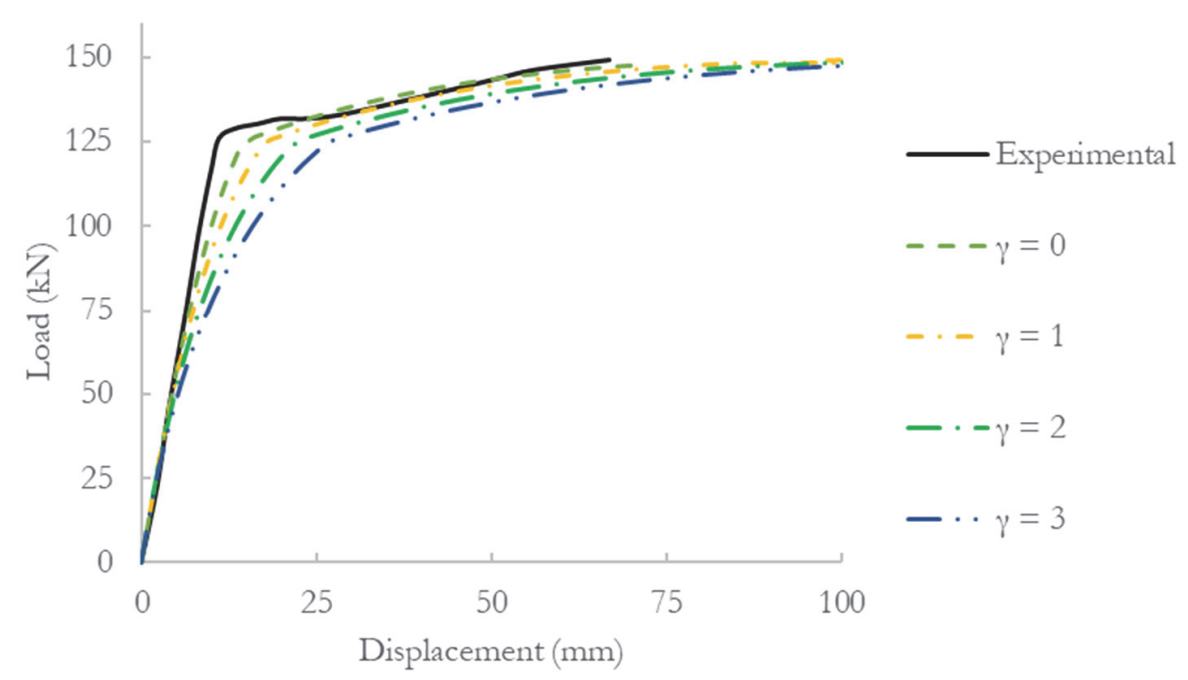

Figure 11: Convergence of results to the experimental B2 [4]

It may be noticed by the experimental data that this beam has a higher stiffness. Thus, $\gamma=0$ provides better results. Moreover, the results obtained by using $\gamma \neq 0$, due to their lower inclination, reaches the collapse load only for higher values of displacement, not fitting well for the three stages.

For B3, with results of load-midspan displacement, presented in Fig. 12, can be observed a less-rigid behaviour. Therefore, the numerical simulation gives better results for higher $\gamma$ values.

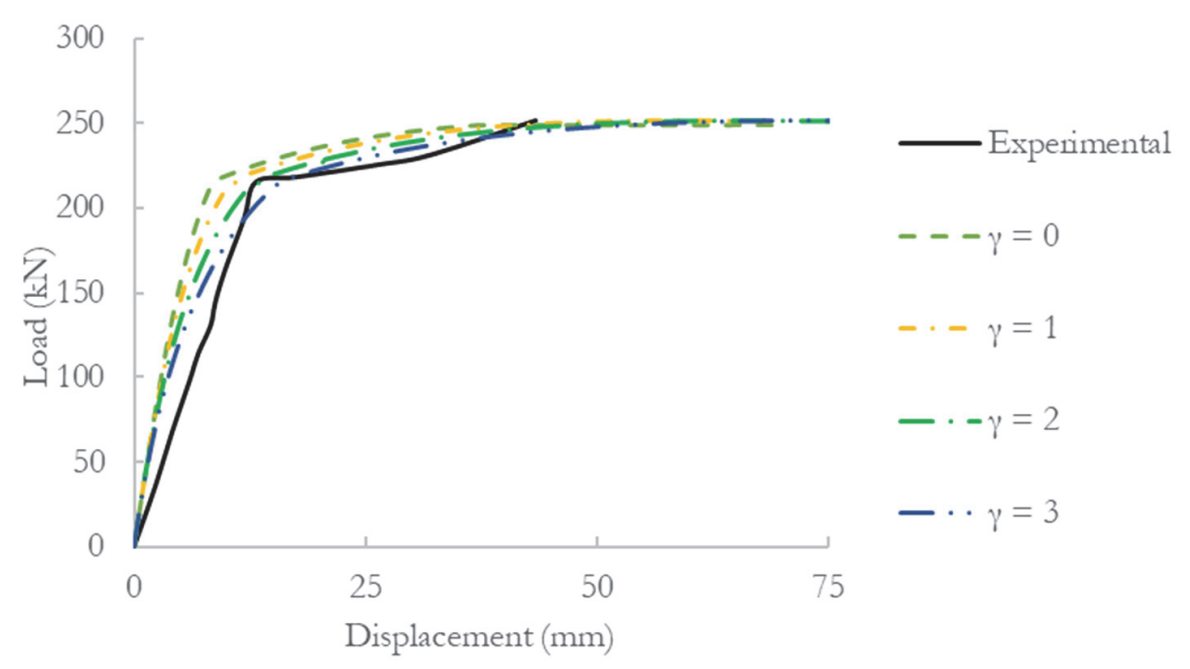

Figure 12: Load-Displacement curve B3 [4]

Brennero Base segment tunnel [5]

Aiming to analyse the performance of a precast tunnel, Caratelli et al. [5] carried out a full-scale test of a tunnel segment. In its totality, the tunnel has $55 \mathrm{~km}$ long, with external diameter equal to 6 meters and total circumference length equal to $19 \mathrm{~m}$. The diameter was divided in 6 segments, where only one was experimentally tested under three points bending, getting the midspan displacement. The set-up of the test is shown in Fig. 13 and its orthogonal view is shown in Fig. 14, where " $\mathrm{t}$ " is the thickness and " $\mathrm{L}$ " is the length between hinge supports. 


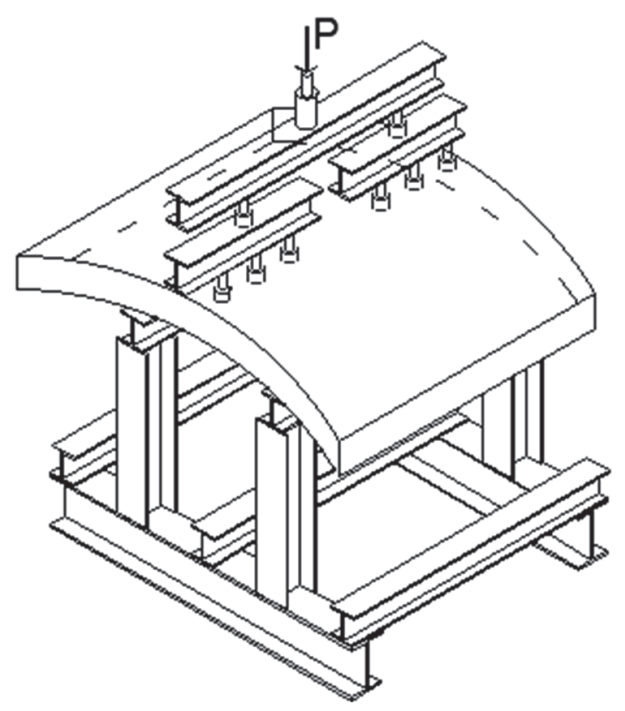

Figure 13: Test set-up [5, 6]

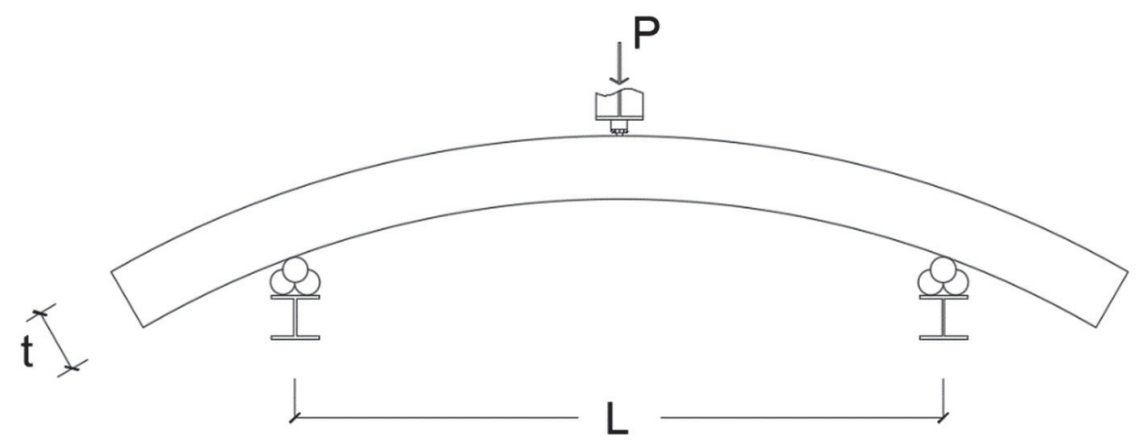

Figure 14: View of the segment of tunnel, in meters

The considered segment thickness is equal to $200 \mathrm{~mm}$, the length between hinge supports and the width are equal to $204 \mathrm{~cm}$ and $150 \mathrm{~cm}$, respectively. Its average cubic compressive strength of concrete reached $50 \mathrm{MPa}$ and the yielding strength of the longitudinal reinforcement is $450 \mathrm{MPa}$. The reinforced is composed with $8 \mathrm{~mm}$ rebars, spaced of $20 \mathrm{~cm}$ and with open stirrups, used as splitting reinforcement, as shown in Fig. 15.

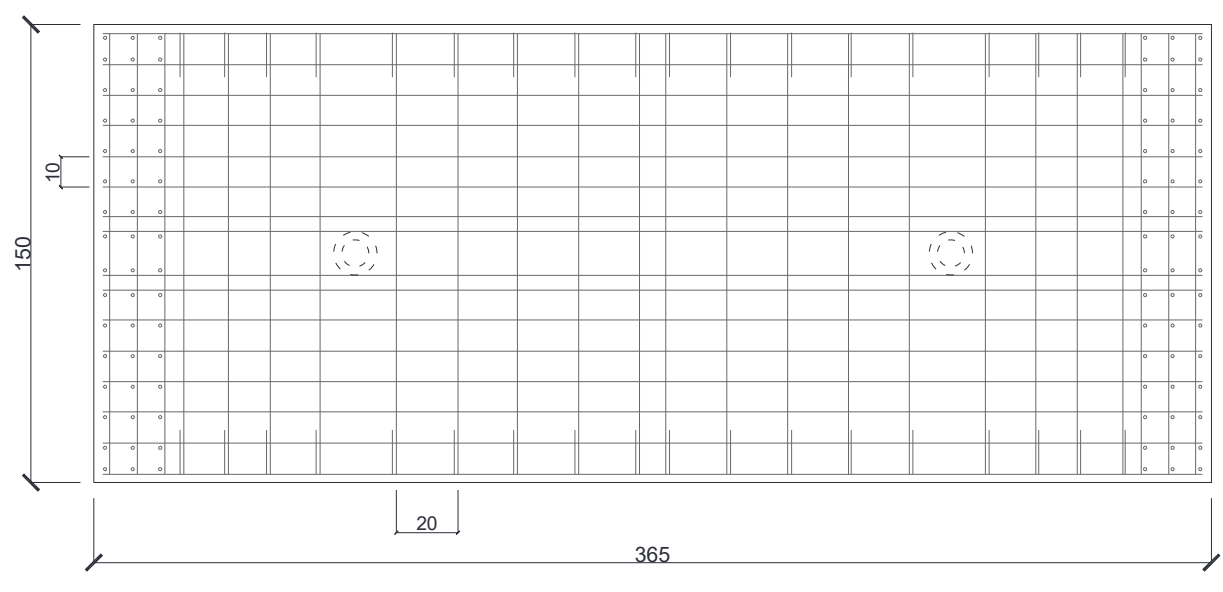

DIMENSIONS IN CENTIMETERS

Figure 15: Geometry and typical reinforcement arrangement of the Brennero Base segment tunnel [5] 
The mid-span displacement of Brennero Base segment tunnel [5] is shown in Fig. 16 for the experimental response and numerical analyses.

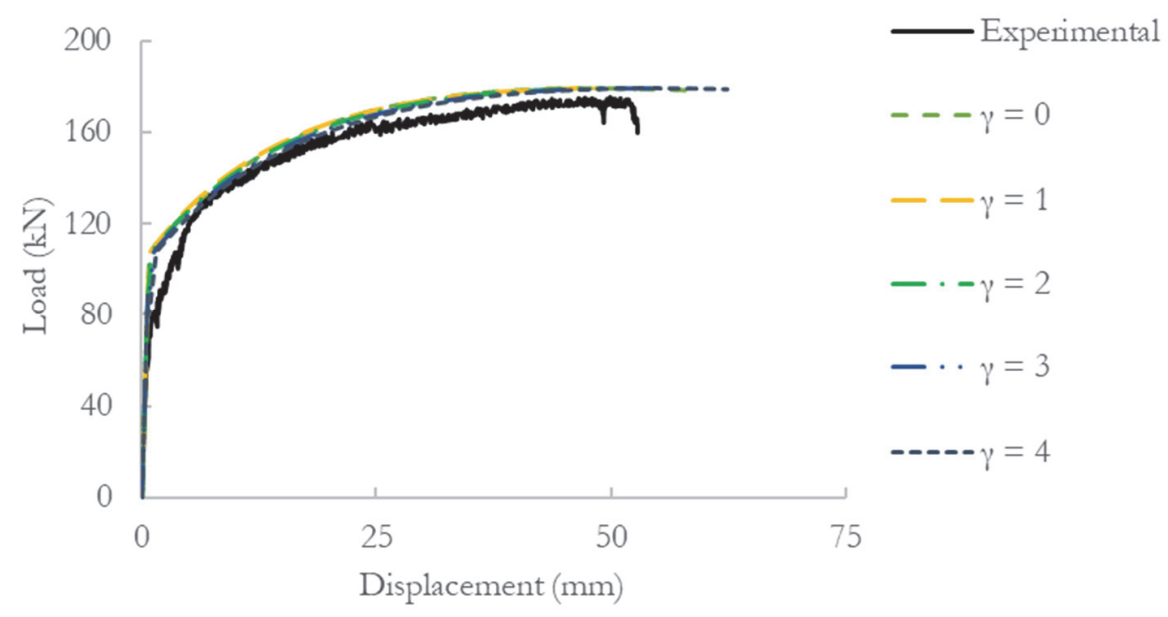

Figure 16: Convergence of results to the experimental of Brennero Base segment tunnel [5]

It can be observed that the results of all analysis were close one another, losing the similarity in the second stage. However, for $\gamma$ equal to 4 , the curve was closer to the experimental data than the others. Furthermore, for all models, the collapse load was bigger than the experimental results, increasing safety.

\section{Canada underground tunnel [6]}

Abbas et al. [6], aiming to study the behaviour of a precast concrete tunnel lining, had modelled a full-scale arc segment from a subway extension tunnel in Canada. For this, they had executed a flexural monotonic and cyclic load test. The arch had distance between supports, width and thickness equal to $300 \mathrm{~cm}, 150 \mathrm{~cm}$ and $235 \mathrm{~mm}$, respectively. The compressive concrete strength equal to $60 \mathrm{MPa}$ and yielding strength of reinforcement equal to $450 \mathrm{MPa}$. The reinforcement arrangement was made with $8.6 \mathrm{~mm}, 11.3 \mathrm{~mm}, 14 \mathrm{~mm}$ rebars and is shown in Fig. 17.

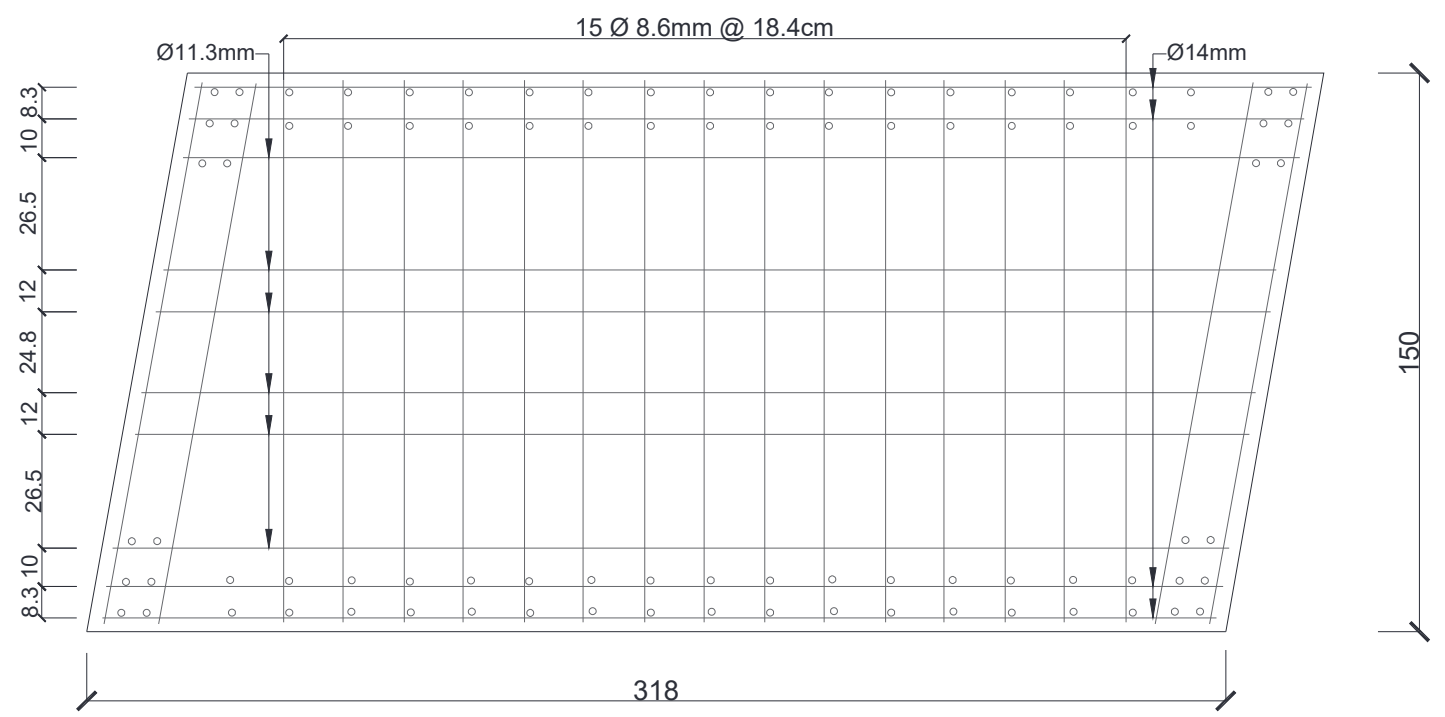

DIMENSIONS IN CENTIMETERS

Figure 17: Geometry and typical reinforcement arrangement of the Canada underground segment tunnel [6] 
The experimental test took place similarly to Brennero Base segment tunnel [5], tested under three points bending, as shown in Fig. 13, and results for the mid-span displacement. The results of the experimental test and the models analysed are presented in Fig. 18.

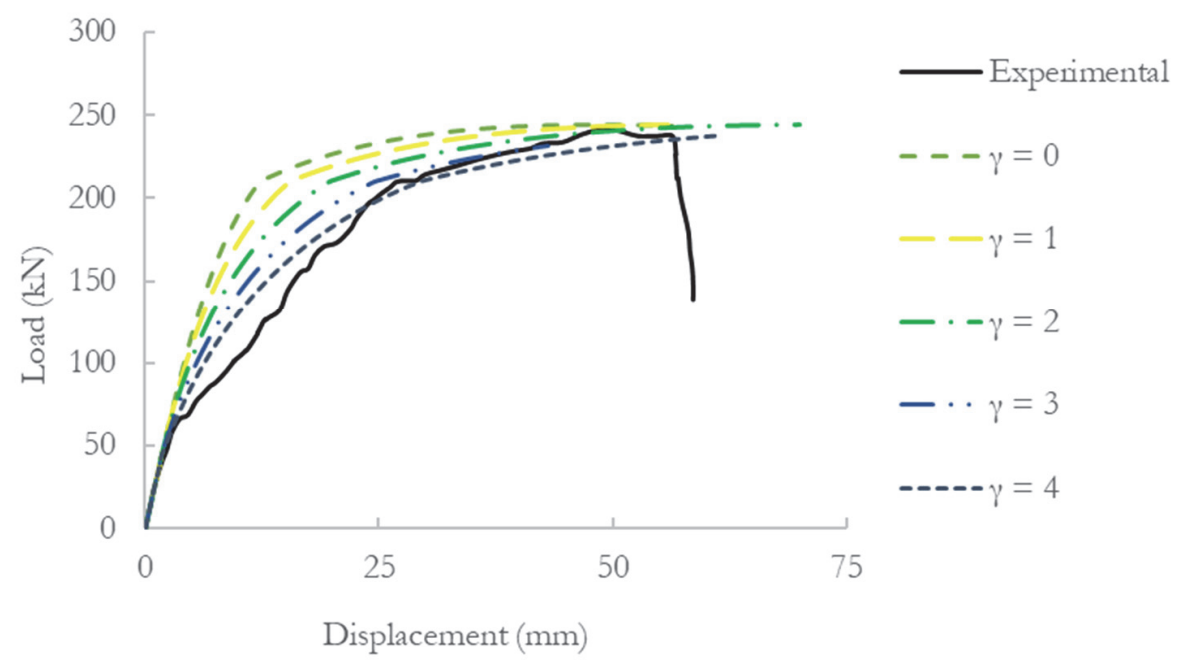

Figure 18: Convergence of results to the experimental of Canada underground tunnel [6]

Note that, the precast segment tunnel was less rigid than Brennero Base segment tunnel [5], so $\gamma>0$ gives better approximation for the results in the curve Load-Displacement. Furthermore, it is shown in Fig. 16, that the results for $\gamma=0$ lost the similarity on cracking and ultimate stages. However, for $\gamma>0$, this similarity is approximate for higher values of $\gamma$, in especial for $\gamma$ equal to 4 , the results are closer than the others. Furthermore, all models could reach to the collapse load, for similar displacements.

Concerning the experimental responses of tunnel lining segments tested by Caratelli et al. [5] and Abbas et al. [6], there are several differences in both set-ups. Note that the geometry of the test is quite different, where the span, thickness and the arc radius of both specimens are $2.04 \mathrm{~m}, 20.0 \mathrm{~cm}$ and $5.90 \mathrm{~m} \mathrm{[5]} \mathrm{and} 3.00 \mathrm{~m}, 23.5 \mathrm{~cm}$ and $2.40 \mathrm{~m}$ [6], respectively. Such characteristics imply that the tunnel segment tested by Abbas et al. [6] is approximately 2.56 times more flexible than the one tested by Caratelli et al. [5].

\section{CONCLUSIONS}

7 his work intended to present a physical meaning for the empiric coefficient proposed by Alva and El Debs [27], which was analysed from comparisons with experiments obtained in the literature.

Even though it is not observed by Alva and El Debs [27], that the proposed model presents limitations of range for the $\gamma$ value model, once adopting negative values, the plastic and ultimate damage tend to null values, which does not have physical significance. While, for positive values of $\gamma$, when analysing the moment-damage curve, it is observed that, for very high values of $\gamma$, the curve does not represent the actual structural behaviour, i.e., for the increase in the value of the damage, the bending moment presents a decreasing rate. The maximum value of $\gamma$ varies according the structural flexibility, first cracking moment, the increase in strength of the structure due to longitudinal reinforcement and the ultimate bending moment.

Applying $\gamma=0$ and $\gamma \neq 0$ approaches to the experiments, a good approximation of both for the experimental results was observed. However, cases which the structures were more rigid, the first model $(\gamma=0)$ achieved better results in primary and secondary stages, reaching good stiffness results, while for less rigid structures the second model $(\gamma \neq 0)$ presented better approximations for higher values of $\gamma$.

For the analysed experiments, $\gamma=0$ presents better solutions for the cantilever beam [43], the first and the second beams presented by Sharifi [4] and the tunnel lining segment tested by Caratelli et al. [5]. On the other hand, better numerical solutions are obtained with $\gamma=10$ for the beam tested by Meneghetti et al. [44], $\gamma=3$ for the third beam presented by Sharifi [4] and $\gamma=4$ for the tunnel lining segment tested by Abbas et al. [6]. 
Furthermore, both models reached the collapse load for all examples; however, for the cases where the values of $\gamma$ were higher, also higher values of deformation were needed to reach the maximum load.

It is recommended for future works to make modifications to the cracking strength equation, in order to obtain results that reach good approximations in comparison with results obtained experimentally, especially for the secondary stage.

\section{REFERENCES}

[1] Vecchio, F.J., Emara, M.B. (1992). Shear deformations in reinforced concrete frames, ACI Struct. J., 89(1), pp. 46-56, DOI: $10.14359 / 1283$.

[2] Carpinteri, A., Ferro, G., Monetto, I. (1999). Scale effects in uniaxially compressed concrete specimens, Mag. Concr. Res., 51(3), pp. 217-225, DOI: 10.1680/macr.1999.51.3.217.

[3] Marsavina, L., Audenaert, K., De Schutter, G., Faur, N., Marsavina, D. (2009). Experimental and numerical determination of the chloride penetration in cracked concrete, Constr. Build. Mater., 23(1), pp. 264-274, DOI: 10.1016/j.conbuildmat.2007.12.015.

[4] Sharifi, Y. (2012). Structural performance of Self-Consolidating Concrete used in reinforced concrete beams, KSCE J. Civ. Eng., 16(4), pp. 618-626, DOI: 10.1007/s12205-012-1517-5.

[5] Caratelli, A., Meda, A., Rinaldi, Z., Romualdi, P. (2011). Structural behaviour of precast tunnel segments in fiber reinforced concrete, Tunn. Undergr. Sp. Technol., 26(2), pp. 284-291, DOI: 10.1016/j.tust.2010.10.003.

[6] Abbas, S., Soliman, A.M., Nehdi, M.L. (2014). Mechanical performance of reinforced concrete and steel fiber-reinforced concrete precast tunnel lining segments: A case study, ACI Mater. J., 111(5), pp. 501-510, DOI: 10.14359/51687101.

[7] Ruggiero, A., Bonora, N., Curiale, G., De Muro, S., Iannitti, G., Marfia, S., Sacco, E., Scafati, S., Testa, G. (2019). Full scale experimental tests and numerical model validation of reinforced concrete slab subjected to direct contact explosion, Int. J. Impact Eng., 132 (September 2018), DOI: 10.1016/j.jijimpeng.2019.05.023.

[8] Broek, D. (1984). Elementary engineering fracture mechanics, Martinus Nijhoff. ISBN: 978-94-009-4333-9.

[9] Shi, Z., Ohtsu, M., Suzuki, M., Hibino, Y. (2001). Numerical analysis of multiple cracks in concrete using the discrete approach, J. Struct. Eng., 127(9), pp. 1085-1091, DOI: 10.1061/(ASCE)0733-9445(2003)129:3(324).

[10] Abo, H., Tanaka, M., Yoshida, N. (2000). Development of a maintenance system for waterway tunnels. Electric Power Civ Eng, 287, 424-6.

[11] Lemaitre J, Chaboche JL (1985). Mécaniques des matériaux solides. Paris: Dunod. ISBN: 978-2100013975.

[12] Bonora, N., (1997). A nonlinear CDM model for ductile failure. Engineering Fracture Mechanics, 58, pp. 11-28, DOI: 10.1016/S0013-7944(97)00074-X.

[13] Ragueneau, F., La Borderie, C., Mazars, J. (2000). Damage model for concrete-like materials coupling cracking and friction, contribution towards structural damping: first uniaxial applications, Mech. Cohesive-Frictional Mater., 5(8), pp. 607-625, DOI: 10.1002/1099-1484(200011)5:8<607::AID-CFM108>3.0.CO;2-K.

[14] Comi, C., Perego, U. (2001). Fracture energy based bi-dissipative damage model for concrete, Int. J. Solids Struct., 38(36-37), pp. 6427-54, DOI: 10.1016/S0020-7683(01)00066-X.

[15] Bažant, Z.P., Jirásek, M. (2002). Nonlocal Integral Formulations of Plasticity and Damage: Survey of Progress, J. Eng. Mech., 128(11), pp. 1119-1149, DOI: 10.1061/(ASCE)0733-9399(2002)128:11(1119).

[16] Proença, S.P.B., Pituba, J.J.C. (2003). A damage constitutive model accounting for induced anisotropy and bimodular elastic response, Lat. Am. J. Solids Struct., 1(1), pp. 101-117.

[17] Comi, C., Perego, U. (2011). Anisotropic damage model for concrete affected by alkali-aggregate reaction, Int. J. Damage Mech., 20, pp. 598-617, DOI: 10.1177/1056789510386857.

[18] Farahani, B. V., Belinha, J., Pires, F.M.A., Ferreira, A.J.M., Moreira, P.M.G.P. (2017). A meshless approach to non-local damage modelling of concrete, Eng. Anal. Bound. Elem., 79, pp. 62-74, DOI: 10.1016/j.enganabound.2017.04.002.

[19] Testa, G., Ruggiero, A., Iannitti, G., Bonora, N., Gentile, D. (2018). Modification of the Bonora damage model for shear failure, Frat. Ed Integrita Strutt., 12(44), pp. 140-150, DOI: 10.3221/IGF-ESIS.44.11.

[20] Majid, F., Elghorba, M. (2018). Continuum damage modeling through theoretical and experimental pressure limit formulas, Frat. Ed Integrita Strutt., 12(43), pp. 79-89, DOI: 10.3221/IGF-ESIS.43.05.

[21] Flórez-López J. (1993) Modelos de daño concentrado para la simulación del colapso de pórticos planos. Rev Int Mét Num Cálc Dis Ing. ;9(2):123-139.

[22] Cipollina, A., López-Inojosa, A., Flórez-López, J. (1995). A simplified damage mechanics approach to nonlinear analysis of frames, Comput. Struct., 54(6), pp. 1113-1126, DOI: 10.1016/0045-7949(94)00394-I. 
[23] Perdomo, M.E., Ramírez, A., Flórez-López, J. (1999). Simulation of damage in RC frames with variable axial forces, Earthq. Eng. Struct. Dyn., 28(3), pp. 311-328, DOI: 10.1002/(sici)1096-9845(199903)28:3<311::aid-eqe819>3.0.co;2d.

[24] Liu Y. -B., Liu J. -B. (2004). A damage beam element model for nonlinear analysis of reinforced concrete member. J Earthquake Eng Eng Vib., 24(02), pp. 95-100.

[25] Araújo F, Proença S.P.B. (2008). Application of a lumped dissipation model to reinforced concrete structures with the consideration of residual strains and cycles of hysteresis. J Mech Mater Struct., 3(5), pp. 1011-1131, DOI: $10.2140 /$ jomms.2008.3.1011.

[26] Rajasankar J, Iyer NR, Prasad AP. (2009). Modelling inelastic hinges using CDM for nonlinear analysis of reinforced concrete frame structures. Comput Concr.,6(4), pp. 319-431, DOI: 10.12989/cac.2009.6.4.319.

[27] Alva, G.M.S., El Debs, A.L.H. de C. (2010). Application of lumped dissipation model in nonlinear analysis of reinforced concrete structures, Eng. Struct., 32(4), pp. 974-981, DOI: 10.1016/j.engstruct.2009.12.024.

[28] Faleiro, J., Oller, S., Barbat, A.H. (2010). Plastic-damage analysis of reinforced concrete frames, Eng. Comput., 27(1), pp. 57-83, DOI: 10.1108/02644401011008522.

[29] Yang, T. -S., Wang, J. -L. (2010). Damage analysis of three-dimensional frame structure suffering from impact. J Vib Shock, 29(12), pp. 177-180.

[30] Perdomo, M.E., Picón, R., Marante, M.E., Hild, F., Roux, S., Flórez-López, J. (2013). Experimental analysis and mathematical modeling of fracture in RC elements with any aspect ratio, Eng. Struct., 46, pp. 407-416, DOI: $10.1016 /$ j.engstruct.2012.07.005.

[31] Amorim, D.L.N.F., Proença, S.P.B., Flórez-López, J. (2013). A model of fracture in reinforced concrete arches based on lumped damage mechanics, Int. J. Solids Struct., 50(24), pp. 4070-4079, DOI: 10.1016/j.ijsolstr.2013.08.012.

[32] Teles, D.V.C., Oliveira, M.C., Amorim, D.L.N.F. (2020). A simplified lumped damage model for reinforced concrete beams under impact loads, Eng. Struct., 205, DOI: 10.1016/j.engstruct.2019.110070.

[33] Guerrero, N., Marante, M.E., Picón, R., Flórez-López, J. (2007). Model of local buckling in steel hollow structural elements subjected to biaxial bending, J. Constr. Steel Res., 63(6), pp. 779-790, DOI: 10.1016/j.jcsr.2006.08.006.

[34] Bai, Y., Kurata, M., Flórez-López, J., Nakashima, M. (2016). Macromodeling of Crack Damage in Steel Beams Subjected to Nonstationary Low Cycle Fatigue, J. Struct. Eng., 142(10), pp. 1-13, DOI: 10.1061/(ASCE)ST.1943-541X.0001536.

[35] Bai, Y., Guan, S., Flórez-López, J. (2017). Development of a damage model for assessing fracture failure of steel beamto-column connections subjected to extremely low-cycle fatigue, Eng. Fail. Anal., 82, pp. 823-834, DOI: 10.1016/j.engfailanal.2017.07.032.

[36] Bazán, J.A.V., Beck, A.T., Flórez-López, J. (2019). Random fatigue of plane frames via lumped damage mechanics, Eng. Struct., 182, pp. 301-315, DOI: 10.1016/j.engstruct.2018.12.008.

[37] Amorim, D.L.N. d. F., Proença, S.P.B., Flórez-López, J. (2014). Simplified modeling of cracking in concrete: Application in tunnel linings, Eng. Struct., 70, pp. 23-35, DOI: 10.1016/j.engstruct.2014.03.031.

[38] Amorim, D.L.N.F., Proença, S.P.B., Flórez-López, J. (2014). Lumped Damage Mechanics as an Alternative to Analyse Masonry Arches. International Collaboration by Young Researchers for "Application of Structural Engineering and Structural Health Monitoring to Historic Buildings, pp. 19-25.

[39] Toi, Y., Hasegawa, K. (2011). Element-size independent, elasto-plastic damage analysis of framed structures using the adaptively shifted integration technique, Comput. Struct., 89(23-24), pp. 2162-2168, DOI: 10.1016/j.compstruc.2011.09.002.

[40] Amorim, D.L.N.F. (2016). On the lumped damage mechanics for nonlinear structural analyses: new developments and applications. Escola de Engenharia de São Carlos.

[41] Amorim, D.L.N.F., Piedade Neto, D., Proença, S.P.B., Flórez-López, J. (2018). The extended lumped damage mechanics: A new formulation for the analysis of softening with FE size-independence, Mech. Res. Commun., 91, pp. 13-18, DOI: 10.1016/j.mechrescom.2018.05.001.

[42] Powell, H.G. (1969). Theory for nonlinear elastic structures, J. Struct. Div.-ASCE, 95 (ST12), 2687-2701.

[43] Flórez-López, J., Marante, M.E., Picón, R. (2015). Fracture and damage mechanics for structural engineering of frames: State-of-the-art industrial applications, Engineering Science Reference. ISBN: 978-1466663794.

[44] Meneghetti, L.C. (2007). Análise do comportamento à fadiga de vigas de concreto armado reforçadas com PRF de vidro, carbono e aramida. Universidade Federal do Rio Grande do Sul.

[45] Alva, G.M.S. (2004). Estudo teórico-experimental do comportamento de nós de pórtico de concreto armado submetidos a ações cíclicas. Engenharia de São Carlos. 